This item was submitted to Loughborough's Research Repository by the author.

Items in Figshare are protected by copyright, with all rights reserved, unless otherwise indicated.

\title{
Industry 4.0 and circular economy: Operational excellence for sustainable reverse supply chain performance
}

PLEASE CITE THE PUBLISHED VERSION

https://doi.org/10.1016/j.resconrec.2019.104583

\section{PUBLISHER}

Elsevier BV

\section{VERSION}

AM (Accepted Manuscript)

\section{PUBLISHER STATEMENT}

This paper was accepted for publication in the journal Resources, Conservation and Recycling and the definitive published version is available at https://doi.org/10.1016/j.resconrec.2019.104583

\section{LICENCE}

CC BY-NC-ND 4.0

\section{REPOSITORY RECORD}

Dev, Navin K, Ravi Shankar, and Fahham Qaiser. 2019. "Industry 4.0 and Circular Economy: Operational Excellence for Sustainable Reverse Supply Chain Performance”. figshare. https://hdl.handle.net/2134/12189543.v1. 


\section{Industry 4.0 and circular economy: Operational excellence for sustainable reverse supply chain performance}

Navin K. Dev (corresponding author)

Department of Mechanical Engineering, Dayalbagh Educational Institute, Dayalbagh, Agra, India

e-mail: navinkumardev@yahoo.com

Mobile No.: +91-9412425551

\section{Ravi Shankar}

Department of Management Studies, Indian Institute of Technology Delhi, New Delhi, India e-mail: ravi1@dms.iitd.ac.in

Mobile No.: +91-9811033937

\section{Fahham Hasan Qaiser}

Nottingham Business School, Nottingham Trent University, Nottingham, UK

e-mail: fahham.qaiser@ntu.ac.uk

Mobile No.: +44-7954331824 


\title{
Industry 4.0 and circular economy: Operational excellence for sustainable reverse supply chain performance
}

\begin{abstract}
The present research proposes a roadmap to the excellence of operations for sustainable reverse supply chain/logistics by the joint implementation of principles of Industry 4.0 (I4.0) and ReSOLVE model of circular economy (CE) approaches. The connection between I4.0 and $\mathrm{CE}$ is unveiled by addressing the case-based model affecting the economic and environmental performances imparting two important dimensions: (i) the information sharing with the reverse logistics system is in real-time mode, and (ii) diffusion of green product in the market. The effectiveness of the virtual world in I4.0 environment is explored using simulation of reverse logistics model involving operations such as inventory and production planning policy, family-based dispatching rules of remanufacturing, and additive manufacturing. The remanufacturing model examines the trade-off between set-up delays and the availability of green transportation. For managerial insights, Taguchi experimental design framework has been used for the analysis. Based on the trade-off analysis between environmental and economic performances, the findings of the paper suggest appropriate combinations of information-sharing and family-based dispatching rules. Further, the findings suggest that, given the I4.0 and circular capabilities, it is necessary to focus on the cost of the socially influenced operations involving factors such as collection investment and size of the end-user market that governs the product returns. Therefore, in the present paper, the integration of I4.0 and CE represents a real-time decision model for the sustainable reverse logistics system.
\end{abstract}

Keywords: operations excellence; sustainable reverse supply chain; Industry 4.0; circular economy; ReSOLVE model; family-based scheduling

\section{Introduction}

In recent years, the emerging digital technologies, such as the internet of things (IoT), internet of services (IoS) and cyber-physical systems (CPS), represents novel paradigms that are rapidly gaining grounds in industrial transformation (Sun et al., 2012). Against this backdrop, Germany presented the ideas of 'Industry 4.0' in 2011 (Kagermann et al., 2011). The industries are looking for a high level of operational excellence through the developments of I4.0 technologies (Mangla et al. 2019). However, to apprehend the benefits concerning I4.0, there needs to establish a procedure for its practical application, especially while studying its impact on operations management (Holmström and Romme, 2012). Moreover, implementing these technologies demands considerable capital expenditure, restraining it to put into practice (Tortorella and Fettermann, 2018).

Considering the above backdrop, operational excellence should be looked at which are economically doable and simultaneously offset the high cost that prevents the adoption of I4.0 principles aiming for sustainable developments. Beside I4.0, other technological-based industrial activities under the premise of operational excellence include reverse logistics, lean operations, six-sigma, inter-organizational information technologies, cellular manufacturing systems, and many other smart manufacturing systems (Mangla et al., 2019). Further, Mangla et al. (2019) identified a few key performance dimensions that need to be addressed in the context of operational excellence to improve sustainable supply chain including flexibility, collaboration, transparency, innovation, and relational capabilities of 
the supply chain (SC). From these performance dimensions, the question related to research arises is: How does the operational excellence influence these performance dimensions?

In view of above discussion, for the purpose of this research work, we look at the operational excellence by considering the integration of characteristics of technology management proposed by Mangla et al. (2019) which include (i) Industry 4.0, (ii) reverse logistics, and (iii) lean approach through cellular manufacturing systems.

\subsection{Technology characteristics of operational excellence}

\subsubsection{I4.0 technologies}

I4.0 technologies can benefit operations management in several ways, such as lowering the processing time of a product, manufacturing cost reduction, up-gradation of value chain coordination, increased process flexibility, better customer service, higher product customization, among others (Fettermann et al., 2018). In the present paper, we position the operations excellence at four maturity levels suggested by Fettermann et al. (2018) involving (i) technologies, (ii) control, (iii) optimization, and (iv) autonomy. The technologies involve real-time information concerning monitoring and reporting at the internal level (e.g. operational units such as inventory-related parameters, set-up time, etc.) and external level (e.g. demand, lead time, order size, transport handling, etc.). The system of operations is controlled through application software at the internal level and the external level of services (e.g. cloud enterprise resource planning (ERP) system equipped with an inventory management module). The level, optimization includes the use of algorithms that can optimize the operations of the system. Finally, a system can adapt to the environment to improve performance at the autonomous level.

\subsubsection{Reverse logistics}

The circular economy is presently an important issue in the manufacturing industry and its interest has widened in recent years among companies and academicians alike. The economically developed and emerging economic countries are promoting to implement $\mathrm{CE}$ in their firms (Sehnem et al., 2019). Kirchherr et al. (2017) proposed to transform the linear forward value chain (i.e. take-make-dispose) process to the circular SC by introducing reuse, remanufacturing, and recycling processes. However, to manage the $\mathrm{CE}$ oriented value chain, the company needs to ascertain managing the recovery and remarketing operations supported by the "Reverse Logistics" (RL) program. CE and RL have a similar focus, for instance, both of them concern about economic and environmental aspects (Reike et al., 2018). However, the CE concept is wider than RL as it is not only covering the reverse sides but also the forward side of the supply chain involving operations of newer materials. Therefore, it is imperative considering sustainable operations management which is vital for the excellence of operations from the CE principles perspective. In view of this, we propose the ReSOLVE framework that characterizes six CE-based business model development strategies (Jabbour et al., 2017): (i) Regenerate, (ii) Share, (iii) Optimize, (iv) Loop, (v) Virtualize, and (vi) Exchange. Specifically, in implementing the ReSOLVE framework, the present research exploits the potentials of RL integrated with I4.0 technologies related to each of the above strategies.

\subsubsection{The lean approach through cellular manufacturing systems}

We look at the lean approach through cellular manufacturing as the operational excellence under technology management suggested by Mangla et al. (2019) mentioned previously. The philosophy of lean is developed concerning the minimization of waste. It is governed by considering various operational practices that facilitate the mitigation of non-value added operations to achieve enhanced resource efficiency. Various researchers have looked at the 
environmental issues of a firm from the perspective of sustainable performance considering lean practices. Further, from the operations point of view, set-up time reduction is an important factor related to inventory optimization that leads to improvement in performance concerning the environment (Jakhar et al., 2018). However, from the CE perspective with remanufacturing as a recovery operation, the system becomes possibly more complex. The researchers found the decisions related to remanufacturing scheduling such as selection of mechanism related to order release, lot sizes, rules concerning priority scheduling, parts commonalities, integration of operations related to forward and reverse supply chain, among others, as challenging issues (Flapper et al., 2002; Kim et al., 2007, Souza, 2013). The present research aims to address the above-mentioned issues through scheduling the remanufacturing process by associating the returns to family-based dispatching (FBD) rules. The concept of FBD rules originated from the idea that products with similar manufacturing set-up requirements can be clustered into families. Typically, it is associated with Group Technology, especially to Virtual Cellular Manufacturing (VCM). VCM suggests that family-oriented scheduling/dispatching rules cause effectiveness in manufacturing (Nomden et al., 2008). The lean operations coupled with information technology-based I4.0 initiatives lead to sustainable developments in the manufacturing/remanufacturing environment from an economic viewpoint (Luthra and Mangla, 2018a). Thus, in the present paper, regarding the set-up requirements due to change in family parts, we explore the remanufacturing operation using additive manufacturing (AM) technology. The companies have started realizing the repercussions of AM technologies by adopting circularity in supply chains for extending the life cycles (Ford and Despeisse, 2016).

From the environmental sustainability and economic performance perspective, the challenges faced by the RL include, how to reach real-time information for various tasks and vehicles with the performances of reducing (i) RL cost, (ii) fuel consumption, (iii) $\mathrm{CO}_{2}$ emission, and (iv) waiting time (Ganzha et al., 2016). Environmental performance concerns the issues of greenhouse gas emission (GHG). The emissions of $\mathrm{CO}_{2}$ as the primary GHG amounts to 28\% from transportation in the US in 2016 (US Environmental Protection Agency), and it amounts to 24\% in the UK in 2015 (Department for Transport, 2017). The CE practices could reduce $\mathrm{CO}_{2}$ emissions by $48 \%$; create a net economic benefit of EUR 1.8 trillion until 2030 in the Europe Union (EU) (Kirchherr et al., 2018). When different modes of transportation are modeled in a network, the efficiency of the operations feeding the terminal has often been neglected although it is the most vital component of the transportation chain. Therefore, it is necessary to explore the feeding system operations that explicitly allow the speed with which the products are fed to the shipping terminal (Bektaş and Crainic, 2007). Keeping this in mind, we model the product remanufacturing under the concept of scheduling by associating them with the FBD rules. The rationale behind using alternative FBD rules is to analyze the effect that allows quicker remanufacturing (representing green products) under inventory and production planning (I\&PP) set-up to transport them through the available mode of transportation with minimum $\mathrm{CO}_{2}$ emission (preferably viá ship). This also positions our work consistent with the suggestion by Jakhar et al. (2018) in which they emphasized to analyze the environmental performance from I\&PP perspective. Now we discuss the key performance dimensions (Mangla et al., 2019) addressing operational excellence to improve sustainable supply chain as mentioned previously.

\subsection{Performance dimensions of operational excellence}

As mentioned earlier, Mangla et al. (2019) identified SC flexibility, collaboration, dynamism, relational capabilities, transparency, and innovation as the performance dimensions responsible for operational excellence to enhance sustainability in a supply chain. We looked 
at these dimensions from the technological characteristics discussed in Section 1.1. From the CE perspective, Urbinati et al. (2017) classified the degree of adoption of CE principles in two key dimensions:

i. The degree to which a firm improve the circularity of its products and processes by leveraging its resources;

ii. The degree to which a firm introduces promotions around the CE through marketing. To accomplish the above-mentioned CE dimensions, two types of complexities need to be managed for recapturing the value through remanufacturing; internal complexities and external complexities. In internal complexities, due to less visibility in reverse logistics, normally firms do not pro-actively carry out their planning and decision-making by taking into account the reverse logistics imperatives, but reactively responses based on the actions of echelons at the downstream (Tibben-Lembke and Rogers, 2002). Since the timing and the number of returns are uncertain, the activities related to I\&PP get complicated (Akçali and Çetinkaya, 2011). This requires collaboration in the form of coordination between functional areas of reverse logistics (Guide Jr., 2000). The realization of components of I4.0 is the technological foundation that identifies with the performance dimensions including collaboration, flexibility, transparency, and dynamism across the circular SC. For example, in I4.0 environment, the collaboration and transparency can be realized through globalized information technology that has enabled to store large data storage in the form of a global cloud system that can be recalled from any place across the different supply chain players. Further, linking the virtual world using simulation tools with the physical environment through CPS which embed sensors and actuators into the application platform provides flexibility by adapting and self-optimizing the dynamic systems.

The external complexities include how remanufactured or green products are promoted. The complexity exists due to the percentage of remanufactured products in the market in comparison to the new products. Therefore, this complexity needs to be addressed through the performance dimension of operational excellence - innovation. We consider the definition of innovation proposed by Roger (2003) that innovation is "... an idea, practice or object that is perceived as new by an individual or other units of adoption". Thus, there is a need to understand the innovation from the diffusion (a pattern in which the innovation is extended among the adopters) perspective as a social system is involved for the decisions of adoption of green products (Schramm et al., 2010; Guarnieri et al., 2016). Mass media and word of mouth are the two means of information that influence the innovated adopters (Bass, 1969). Therefore, to understand the behavior of the consumer, we consider an extended Bass (1969) model that governs the return rate of green products in the RL. The dynamic behavior of two complexities is jointly dealt with by building a simulation model for investigating sustainable performances.

Considering the above discussion, the present research is among the first endeavors in literature, the novelty of which relies on addressing the three main research questions under the premise of operational excellence; technological characteristic of lean approach and performance dimension of innovation of a sustainable reverse logistics system.

(i) How the synergies of I4.0 and CE have an impact on environmental and economic performances?

(ii) How the integration of innovations in terms of diffusion of green products and I\&PP policy affect a reverse logistics system in terms of its performance?

(iii) How different FBD rules affect the speed with which the products are fed to the shipping terminal and thereby affect the performances?

This paper is organized as follows. In Section 2 we carried out a literature survey and outlined the research contribution. Section 3 illustrates the system description involving the framework of the case-based transportation system, reverse logistics, I4.0, and CE defined 
from the Bass model and scheduling rules point of view. The findings of the study are discussed in Section 4.0, while the conclusions derived from the paper and final observations, implications, limitations, and directions for future research are discussed in Section 5 .

\section{Literature review}

\subsection{I4.0, operations management, and sustainability}

The ideas of I4.0 emerged in the manufacturing area for the first time in 2011 (Kagermann et al., 2011). Some initial directions related to I4.0 implementation were provided by a few researchers including (Hermann et al., 2016; Chukwuekwe et al., 2016). However, the existing research in literature still requires consistent knowledge about how I4.0 is going to affect the companies' operations management of future industries. Therefore, we find scarce studies concerning contributions of I4.0 in which some framework or practical repercussions related to operations management are reported (Fettermann et al., 2018). The processes that become automated due to I4.0 technologies effects potentially in enhancing the performance of all the activities concerning operations management. For instance, real-time information on operational units such as material flow, customers' demand, and inventory position of SC echelons are some of the applications. CPS enables the integration of cyberspace, physical processes and objects in order to develop a link between various resources and information equipment in the manufacturing network. This helps in prioritization in scheduling operation in the environment of real-data availability (Ahmadov and Helo, 2016). For gathering and distributing real-time data, sensors and actuators play an important role (Yu et al., 2015). For instance, in a cloud-based manufacturing environment, the bin inventory management is carried out viá RFID in the third generation CPS system (Singh et al., 2015).

The internet enables the sharing of operational resources by creating a virtual space using cloud manufacturing technology. Developing the service base for all the players of a supply chain interaction for design, manufacturing, and assembly is the reason behind cloud manufacturing. Additive manufacturing is another technology that is enabled through cloud services of I4.0. From the operations management perspective, AM machines do not require machine set-ups involving processes such as changing of tools, jigs, and fixtures (Huang et al., 2013). Unique identification code allows sharing real-time data among all echelons of a supply chain under IoT capabilities. It also provides a link between machines, modes of transportation, and the internet (Zhong et al., 2017).

In the contemporary system of operations, I4.0 and sustainability play a significant role. The synergy of both has the potential to move the sustainable society further (Dubey et al., 2017). The environmental and economic issues of organizations' operations management are dealt with potentially viá simultaneous development of I4.0 and sustainability (Elkington, 1994; Gunasekaran and Irani, 2014). In the decision-making of sustainable operations that are environmentally influenced, involve the green design of products and process and environmentally driven supply chain operations (Gunasekaran et al., 2014; Abdul-Rashid et al., 2017). The decision-making process for the classification of environmentally-sustainable operations suggested by González-Benito and González-Benito (2006) include: (a) design of environment, corresponds to reuse, remanufacture, and recycle in order to reduce waste, (b) cleaner production, corresponds to reduction of resource consumption and generation of waste viá production planning and control processes, and (c) green supply chain management, corresponds to reduction of environmental effect due to transportation and encouraging green purchasing and responsible recovery system. Alayón et al. (2017) suggested implementing 3Rs (reduce, reuse, recycle) for environmentally-sustainable operations. It is, therefore, evident that the associations between environmentally-sustainable 
operations and I4.0 are valuable, due to the significance of technology in carrying out environmentally-sustainable oriented operations excellence decisions.

\subsection{CE and sustainable operations management}

$\mathrm{CE}$ is a promising approach concerning sustainable operations management intended for sustainable use of resources (McDowall et al., 2017; Sehnem et al., 2019). Ghisellini et al. (2016) suggested retaining the value of resources at the end of their life cycle to capitalize on the circularity process. Zhao and Zhu (2015) proposed the processes, viź, reuse, remanufacturing, and recycling as the sustainable strategies of CE. MacArthur et al. (2015) proposed the CE principles oriented ReSOLVE framework that includes:

(i) Regenerate - based on the conversion of waste into a source of energy for different operations along the value chain.

(ii) Share - based on the sharing of resources to extend the life cycle viá recovery operations from the economic point of view.

(iii) Optimize - based on technology-centered strategy, which requires the organization to use digital manufacturing technology such as principles of I4.0 to reduce waste in the operations system across the supply chains.

(iv) Loop - based on the restoration of the value of products viá recovery operations.

(v) Virtualize - based on the service-focus strategy that allows virtual and dematerialized products.

(vi) Exchange - based on introducing advanced and renewable goods instead of old and non-renewable goods.

Along the lines of the above-mentioned elements of the ReSOLVE framework, Urbinati et al. (2017) pointed out that the CE business models should be based on diminishing the reliance on new materials, and should move to the renewable energy-based system to enhance embracing the sustainable operations practices.

From the operations management perspective, Matsumoto et al. (2016) suggested the integration of forward SC with RL for operations such as raw material purchasing, planning, production, marketing and distribution for realizing the sustainable potential of CE. Urbinati et al. (2017) pointed out that the business models have not considered the degree of adoption of circularity; they are studied under a Boolean 'on' or 'off' approach. Urbinati et al. (2017) identified three degrees of adoption of circularity; downstream circular adoption, upstream circular adoption, and full circular adoption. Downstream circular adoption involves a marketing campaign for the reused or remanufactured products, whereas the upstream circular adoption concern only with the activities that establish an effective relationship with the supplier. However, the full adoption involves the adoption of circularity at both the external and internal levels of the firm. That is, the circularity is managed at the internal operations system level as well as the involvement of the supplier in its circular operation system is considered. Further, the firms with full circular adoption communicate clearly to the customers regarding their circular practices through promotional marketing campaigns.

Some studies in the literature have shown the connection between I4.0 and organizational sustainability (Stock and Seliger, 2016). Therefore, it is evident to explore this connection, which is developed in the next section.

\subsection{I4.0, CE, and operations management}

The information-sharing in contemporary supply chains is a significant example of the contribution of I4.0 capabilities. This has enhanced sustainable operations management decisions (Stock and Seliger, 2016). Thus, the implementation of an integrated approach of I4.0 and the principles of CE can provide leverage to sustainable operations management. 
Sustainable operations management requires an understanding of production operations that affect the environment and need to focus on the efficiency and effectiveness of operations management as well (Kleindorfer et al., 2005). Thus, considering sustainable operations management, we discuss the principles of CE aligned with I4.0 technologies. According to Jabbour et al. (2018), the components of CE:

(i) Regenerate - aligns with I4.0 by making sustainable production decisions based on adapting data received viá IoT.

(ii) Share - aligns with I4.0 through the use of both cloud-based resources and IoT. The potential of this component of $\mathrm{CE}$ could be realized through sharing information related to inventory management, supply, and demand across the SC and the consumers as well. These technologies can collect information concerning society's dynamic behavior so that the organization can improve both operational parameters and resource utilization for environmental and economic performances (Rymaszewska et al., 2017).

(iii) Optimize - aligns with I4.0 supported by CPS and IoT. These technologies can collect information in the form of data from processes and various resources to enable identifying work-in-process inventory, which helps in computing optimal order size. Suppliers help in managing their own as well as the production planning of system-wide supply chain (Hofmann and Rüsch, 2017), and conformance to environmental issues viá RFID tags and IoT.

(iv) Loop - aligns with I4.0 supported by IoT, CPS, and cloud services. It represents a broad aim of the circularity of materials and energy. The operations in reverse logistics such as tracking and tracing of products and transportation modes could be improved using sensors, RFID tags, etc. Accordingly, the recovery processes such as reuse, remanufacture, and recycle of components could be carried out (Vanderroost et al., 2017). Cloud services could support the organization by using AM technology when the workload is distributed over the supply chain (Ford and Despeisse, 2016).

(v) Virtualize - aligns with I4.0 supported by cloud manufacturing, IoT, and AM technologies. These technologies enable the relationship between organizations, suppliers, and customers such that the physical world is replaced by the virtual world using simulation models by linking to sensor data (Stock et al., 2018). AM technology enables customized products based on interactions among manufacturers, suppliers, and customers.

(vi) Exchange - aligns with I4.0 by adopting additive manufacturing and IoT. AM enables sustainable production through reduced use of material and recovery operations (Despeisse et al., 2017).

\subsection{Green product diffusion and remanufacturing}

As pointed out in Section 1, given the new market for the sale of the same product, the product returns causes problem concerning the cannibalizing of remanufactured products (Atasu et al., 2008). The situations of imperfect substitution are less investigated in the existing literature (Wei et al., 2015; Guarnieri et al., 2016). As discussed in Section 1, green product adoption involves social influence that entails an individual's characteristics of innovation. In the marketing literature, we find many researches concerning the diffusion of new products or policies concerning promotion. The classical Bass diffusion model (Bass, 1969) is the best-known example. Some other researches include (Karmeshu et al., 2011, Amini and $\mathrm{Li}$, 2015). A few researches have proposed diffusion models concerning remanufactured or green products (Atasu et al., 2008; Olson, 2013). 
As mentioned in Section 1.2, operations of RL have always been an important concern to extend the life cycle of a product to maximize value creation. From the operations management perspective, some researches investigated reverse logistics from I\&PP system perspective (Kumar and Rahman, 2014; Dev et al., 2017; Dev et al., 2019). Dev et al. (2017) investigated a closed-loop hybrid system of remanufacturing for five different inventory review policies using discrete event simulation. Wang et al. (2017) analyzed the component obscelence in the life cycle of a product and the delay in reprocessing operations in reverse logistics. They studied economic benefits involving volume due to reuse using the Bass model. However, the researches mentioned above considered the reused components as the exact replacements for the new-manufactured parts and did not consider any green incentives as a promotional policy for the green products' adoption. A recent work that deals with issues similar to those addressed in the present research is by Dev et al. (2019). Dev et al. (2019) analyzed the RL system for environmental and economic performance. The generation of product returns is realized through the Bass (1969) model. However, in addition to the issues addressed by Dev et al. (2019), the present research has exploited the FBD rules for the speed with which the products are fed to the terminals of transportation. The transportation cost and $\mathrm{CO}_{2}$ emission are included in the measures for environmental and economic performance.

Furthermore, the current paper is framed to explore the need for integrating the principles of I4.0 technologies and the ReSOLVE framework of CE for analyzing an RL system. The performances related to the economy and environment of an RL system are used as the measures of operational activities that represent offsetting the realization of high cost in the implementation of I4.0 technology. Accordingly, consistent with Mangla et al. (2019), the following research objectives are outlined which are aligned with the research questions mentioned in Section 1.2 concerning operational excellence for a sustainable reverse logistics system and simultaneously attempt to address the full adoption of circularity consistent with Urbinati et al. (2017).

(1) To study the downstream circular adoption by focusing on how customer behavior under the operational excellence dimension of innovation influence the return rate under the premise of I4.0 technologies.

(2) To study the upstream circular adoption by focusing on how the recycled-material supplier internal to the supply chain controls the effect of uncertainties associated with the returns in light of coordination between various echelons and manage the operations in terms of I\&PP and sustainable transportation activities using I4.0 technologies.

To our knowledge, the present research is among the very first endeavor that aims to position the above objectives towards the body of knowledge in the joint application of principles of I4.0 and CE by linking to a virtual reverse logistics model. The potentials of the simulation model under the notions of virtual world environment are analyzed in resolving the above issues for the sustainable performances of reverse logistics at large.

\section{System description and mathematical modeling}

\subsection{Case based transportation network system}

In this study, we consider a circular chain of a refrigerator manufacturer. We present a hypothetical but realistic case of alternative transportation for a refrigerator company situated at Pondicherry in India. The refrigerator company is quite liberal in the end-of-life recovery process. Their product design ensures that 85 to 90 percent of the materials (steel, plastics, etc.) used in the refrigerator can be recycled. The company carries out collection, dismantling, and recycling processes of e-waste collected from all over India. For these operations, the company has partnered with an authorized e-waste recycler to collect the 
products from the consumers' homes after their end-of-life and perform the recovery processes.

Although, the refrigerator company covers a large number of distributors throughout India, in the present study we consider single origin-destination transportation, i.e. from Pondicherry to Bhavnagar (Gujrat). The company has not so far started shipping their products through sea routes within India. However, in the present study, to explore the sustainability practices, we assume truck, rail, and ship as the transportation modes (M) running across the network. To focus on the sustainability aspect, we promote the transportation of remanufactured products via ship with the notions that the ship has the least carbon emission. Subsequently, given the availability of mode of transportation, we prioritize the sequence of transportation as the ship, train and then the truck.

As mentioned in Section 1.1.3, the FBD rules are analyzed with the implication that speed with which the products are fed to the shipping terminal is important from the efficiency of the transportation chain viewpoint. The rationale behind using alternative FBD rules is to analyze the effect that allows quicker remanufacturing (representing green products) under the AM environment to transport them through the prioritized mode of transportation (i.e. viá ship in the present case).

The total transportation costs involving the load of the moving vehicle include variable and fixed costs. The variable involving transportation cost is per unit weight of the product, which includes mover's overhead costs, administration costs, costs of crew, and fuel costs. We consider that the variable concerning the cost of transportation is constant over time and that they depend only on the carrying weight and transportation mode. The fixed cost largely consists of operators' wages and the cost of handling incurred for moving the products on and off the vehicles. We assume constant values of fixed costs for the truck, rail, and ship at $\$ 50, \$ 100$, and $\$ 150$ respectively.

\subsection{Estimation of emissions}

We consider the route distance and time for ship, rail, and road to transport the refrigerators from Pondicherry to Bhavnagar (Gujrat) provided by Google Maps. We consider the values of capacity, the unit variable cost, waiting time charges at the terminal per unit time, and $\mathrm{CO}_{2}$ emissions factors for each mode consistent with Qu et al., (2016) as shown in Table 1. This does not abdicate our key focus of the study to analyze the effect of FBD rules on the transportation system.

Table1: Parameters of transportation

\begin{tabular}{|c|c|c|c|c|c|}
\hline $\begin{array}{c}\text { Transportation } \\
\text { mode }\end{array}$ & $\begin{array}{l}\text { Capacity* } \\
\text { (Tonne) }\end{array}$ & $\begin{array}{c}\text { Variable cost } \\
(\$ \text { per ton- } \\
\mathrm{km})\end{array}$ & $\begin{array}{c}\text { Waiting time } \\
\text { charges at } \\
\text { terminals (\$ per } \\
\text { hr.) }\end{array}$ & $\begin{array}{c}\mathrm{CO}_{2} \\
\text { (g/tonne } \\
-\mathrm{km})\end{array}$ & $\begin{array}{l}\text { Distance to } \\
\text { Dealer } \\
(\mathrm{Km})\end{array}$ \\
\hline Truck & 10 & 0.051 & $\begin{array}{c}33 \text { per } 28 \text { feet } \\
\text { trailer }\end{array}$ & 62 & 1900 \\
\hline Rail & 40 & 0.060 & $\begin{array}{l}7.5 \text { per } 20 \text { feet } \\
\text { container }\end{array}$ & 22 & 2240 \\
\hline Ship & 100 & 0.035 & 6.5 per GRT & 16 & 2600 \\
\hline
\end{tabular}

* Weightof one refrigerator is assumed as 1 tonne

Consistent with Park et al. (2012), in the present model, we have used the activity-based approach for estimating the $\mathrm{CO}_{2}$ emissions in intermodal transportation. The $\mathrm{CO}_{2}$ emission is estimated by equation (1) as:

$l \times d \times e$ 
where $l$ (in tonnes) is the load carried by the vehicle over a distance of $d$ (in kilometers) and ' $e$ ' is the average $\mathrm{CO}_{2}$ emission factor (in $\mathrm{g} /$ tonne-km). The $\mathrm{CO}_{2}$ emission is converted into monetary units; in particular, we use $\$ 100$ per tonne ( $\mathrm{Qu}$ et al., 2016). The above $\mathrm{CO}_{2}$ function allows easy implementation in simulation. The variables including distance and the total weight can be captured in simulation, at the same time neglecting the parameters that are difficult to compute, for instance, different types of fuels used in different transportation modes.

\subsection{Reverse logistics framework}

We designed the framework of the reverse logistics processing system under the conjecture that the returned product has some common parts from the manufacturing process perspective. The commonality is considered to be a characteristic of modularity (i.e., a grouping of components sharing common characteristics). Also, the modules with similar manufacturing processes are considered as families of modules. The refrigerator comprised of various modules, for instance, (i) door, that include outer and inner housing, water supply parts, rubber strip and handle, (ii) cooling system, that include base pan, compressor, dryer, condenser and fan, (iii) evaporator and inner partition, that include evaporator, water tank, shelves, crisper, auger motor, relay capacitor, evaporator cover and back inner.

We consider a closed-loop system consists of a distributor, a manufacturer, a recycled-material (RCY) supplier, and a new-raw-material (NRM) supplier. The distributor is situated at Bhavnagar (Gujrat) in India, while the manufacturer, the RCY supplier, and the NRM supplier are situated at Pondicherry (Tamil Nadu) in India. We assume that the RCY supplier and the NRM supplier are situated in close vicinity of the manufacturer and the delivery lead time to the manufacturer is considered stochastic as $\operatorname{Norm}(1,0.2)$. The demand for the products is realized by the manufacturer and is satisfied by the distributor. The average lead time of the distributor is obtained from the simulation run as each mode of transportation has different distances and speeds. The manufacturer has two available options for the procurement of the raw material/sub-assemblies; either procuring it from the NRM supplier $(n)$ or from the RCY supplier $(r)$ to manufacture the products. The procurement is designed based on the ordering policy mentioned in Appendix A. The raw material/module assembly is supplied to the manufacturer from the inventory of the respective suppliers. The product returns from the consumers are collected at the RCY supplier. The quantity of product returns is based on the innovation theory (Bass) model under the influence of varying information-sharing policies explained in the section ahead. To collect the product-returns from the consumers, the RCY supplier takes collection lead times and is considered to be stochastic as $\operatorname{Norm}(8,0.5)$. The raw material is assumed to arrive from the environment to the NRM supplier that takes time for production which is considered to be stochastic as $\operatorname{Norm}(12,1)$.

Consistent with Guide (2000), we consider a typical recycling facility consists of three distinct processes by the recycled-material supplier: disassembly and recycling, remanufacturing, and reassembly. We focused on the remanufacturing process from the FBD point of view. In the RL, for the sake of tractability of the results, we consider two partfamilies based on the sequence of operations after the disassembly and recycling of a module. Further, we consider one AM machine deployed for the remanufacturing process such that the AM machine is capable of processing either of the product family by changing the CAD program over time. We assume that there is no interruption in receiving part families from disassembly and dispatching them to the queue for processing at AM machine. This does not forfeit our main idea of analyzing the alternative FBD rules in the remanufacturing process. We considered the remanufacturing set-up for FBD rule consistent with Dev et al. (2014); first-come family (FCFAM) and minimum average set-up time (MAS). However, Dev et al. 
(2014) carried out the analysis of two dispatching rules for the forward supply chain system and the load of the manufacturing shop was controlled by the backorders of the warehouse. On the contrary, in the present study system of remanufacturing, we compared the abovementioned FBD rules from the RL perspective to analyze that how the alternative FBD rules allow quicker remanufacturing (representing green products) so as to transport them through the prioritized mode of transportation (i.e. viá ship in the present case). We reiterate that, in the present research, the load of the remanufacturing shop is controlled by the returns obtained through the Bass model discussed in this section ahead.

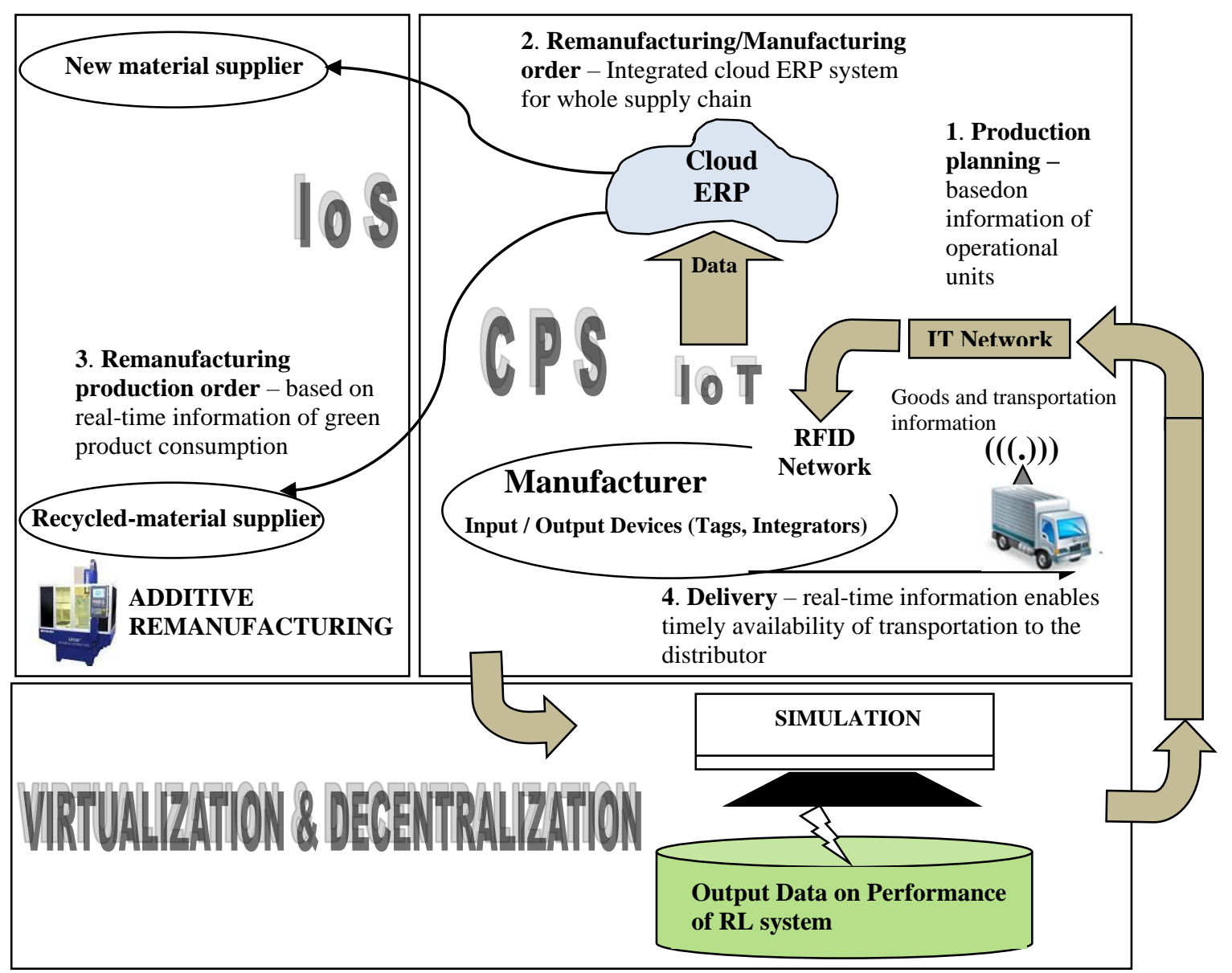

Figure 1: Reverse logistics system according to principles of Industry 4.0.

\subsection{Integration of I4.0 and CE}

Table 2 illustrates how the characteristics of I4.0 and CE have the implications for the proposed RL model. Since the RL model particularly relies on I\&PP, information transparency, AM oriented remanufacturing, and well-coordinated transportation system, we compare the characteristics of I4.0 and ReSOLVE characteristics of CE from these operations perspective. The illustration of typical processes and activities of the RL system highlighting the characteristics of I4.0 is shown in Figure 1.

RFID technology provides leverage to I\&PP (operation 1 in Table 2) of the RL system. Moreover, cloud technology provides a common platform from where the information can be shared among all the entities involved in a supply chain. The order to the NRM supplier or the RCY supplier automatically triggers on the information of the consumption of products. Thus, the demand at the point-of-sale is realized by the production in a real-time manner (operations 2 and 3 in Table 2). Specifically, for the timely delivery of 
green products, the availability of the preferred mode of transport (ship) is ensured through real-time information (operation 4 in Table 2).

\subsection{Returns system based on Innovation theory (Bass) model}

As mentioned in Section 2, environmental decisions are greatly influenced by customer behavior. In the present research, the notions of customer behavior have been explored concerning the social system in which the decision of adoption of remanufactured products or green products is made by the individual consumer. The uncertainty in the volume of returns significantly affects the operations of RL. The possible reasons include (i) the end-of-life of the product, and (ii) the green product diffusion in the market. Given the behavioral changes in the consumers towards green products, in an attempt to adopt the recovery process, the company has to identify its operations for the enhancement of their efficient and effective performances. Consistent with Dev et al. (2019), the realization of consumer behavior and thereby the number of returns are exploited using an extended form of Bass (1969) model. Thus, the relation for the number of returns $(R)$ from the end-user market can be stated involving end-user market capacity $N$ and the cumulative adoption $x(t)$ until time $t$ (Equation 2).

$$
R=\left(\alpha+\frac{\beta}{N} x(t)+\sqrt{\frac{g_{i}}{\delta}}\right)(N-x(t))
$$

where

$N=$ market capacity with a Poisson distribution Pois $\left(\mu_{N}\right)$,

$x(t)=$ the number of customers accepted the green products by time $t$,

$\alpha=$ coefficient of innovation corresponding to green product adopters of their own accord,

$\beta=$ coefficient of imitation corresponding to the imitator customers,

$\sqrt{g_{i} / \delta}=$ green investment $g_{i}$ per period representing the effect of promotion, whereas $\delta$ is the scaling parameter.

Thus, the extended variable $\sqrt{g_{i} / \delta}$ in the Bass model represents the promotional policy concerning a green investment that decides the effect on the number of returns. Savaskan and Wassenhove (2006) have used a similar form of function concerning promotional incentives representing the advertising response model. The other notations used in the model are shown in Appendix-A.

\subsubsection{Model assumptions}

In addition to the assumptions considered by Dev et al. (2017) for the CLSC system, we consider the following assumptions concerning transportation and FBD rule systems.

- For calculating the waiting time of the ship, train, and truck at their respective loading terminals, we consider berth charges, train terminal service charges, and truck trailer parking charges respectively in the total transportation cost. We consider 40 GRT (Gross Registered Tonnage) ship for the transportation of refrigerators via' ship. The berth charges of $\$ 6.5 / \mathrm{hr}$./GRT are considered (APM Terminals, 2019). In rail transportation, we consider a 20 feet container. The terminal service charges for the container is $\$ 7.5 / \mathrm{hr} . / 20$ feet container as the waiting charges (CONCOR, 2017). In the transportation via' truck trailer, we consider the parking charges of the trailer as \$33/hr./28 feet trailer related to the waiting charges (AMEYA Logistics, 2019). 
Table 2: Principles of I4.0 and ReSOLVE for the proposed RL model

\begin{tabular}{|c|c|c|c|}
\hline $\begin{array}{c}\text { Proposed RL model } \\
\text { operations }\end{array}$ & I4.0 scenario in proposed model & I4.0 principles & ReSOLVE principles \\
\hline $\begin{array}{l}\text { 1. Production planning } \\
\text { based on the information } \\
\text { of operational units }\end{array}$ & $\begin{array}{l}\text { ERP receives the information of operational units } \\
\text { (inventory review period, lead times, demand, } \\
\text { etc.) of RL. } \\
\text { In the real-time mode, CPS helps in } \\
\text { managing the ERP system connected over IoT } \\
\text { through RFID that provide data related to } \\
\text { operational parameters. }\end{array}$ & $\begin{array}{l}\text { Interoperability/interconnections and real-time } \\
\text { capabilities - CPS system provides information } \\
\text { concerning operationa units to the ERP system } \\
\text { viá RFID. }\end{array}$ & $\begin{array}{l}\text { Share, and Optimize - End-of-life of the } \\
\text { product is considered from remanufacturing } \\
\text { perspective involving coordination between } \\
\text { RL partners facilitated by IoT. }\end{array}$ \\
\hline 2. Remanufacturing order & $\begin{array}{l}\text { Three information mechanisms are modeled } \\
\text { concerning generation of returns using Bass } \\
\text { model: (i) the green investment is triggered after } \\
\text { each fixed period information, i.e., in a } \\
\text { decentralized way (ii) the order is triggered on } \\
\text { receiving an information of re-order point of } \\
\text { recycled-material supplier inventory levels } \\
\text { (RCYINF), and (iii) the order is triggered on } \\
\text { receiving an information of re-order point of } \\
\text { manufacturer inventory levels (MNFINF). }\end{array}$ & $\begin{array}{l}\text { Service orientation - CPS system allows web- } \\
\text { based ERP system is used for managing the } \\
\text { real-time data across the system-wide supply } \\
\text { chain. }\end{array}$ & $\begin{array}{l}\text { Share, Optimize, and Loop mechanism - } \\
\text { Collaboration and coordination in RL is } \\
\text { realized through intelligent devices to convert } \\
\text { waste into useful resources and information of } \\
\text { post-consumption products is made available } \\
\text { for accurate ordering procedures. }\end{array}$ \\
\hline $\begin{array}{l}\text { 3. Remanufacturing using } \\
\text { AM machine by recycled- } \\
\text { material supplier, and } \\
\text { order of material by the } \\
\text { new-raw-material supplier. }\end{array}$ & $\begin{array}{l}\text { Given the real-time information viá IoS system, } \\
\text { the green promotional activities are triggered by } \\
\text { the recycled-material supplier. }\end{array}$ & $\begin{array}{l}\text { Service orientation - CPS system allows web } \\
\text { service at the system-wide supply chain. }\end{array}$ & $\begin{array}{l}\text { Share, Optimize, and Loop mechanism - } \\
\text { Information of (i) consumption of green } \\
\text { products and (ii) generation of green product } \\
\text { requirement according to the Bass model } \\
\text { incorporated in the ERP system. }\end{array}$ \\
\hline $\begin{array}{l}\text { 4. Delivery - Information } \\
\text { sharing allows effective } \\
\text { delivery of remanufactured } \\
\text { parts by the supplier. }\end{array}$ & $\begin{array}{l}\text { The virtual RL model receives information viá } \\
\text { RFID and CPS system. } \\
\text { The output of simulation of virtual model } \\
\text { helps in evaluation of RL performances for } \\
\text { different input opreational data. } \\
\text { Simulation model also helps in calculating } \\
\text { adequate transportation in terms of timing. } \\
\text { CPS helps in sending back the output of } \\
\text { simulation to the business process in a real-time } \\
\text { for reconfiguration of operational units in order to } \\
\text { maintain the performances of the RL system. }\end{array}$ & $\begin{array}{l}\text { Virtualization and decentralization - The CPS } \\
\text { is linked to the virtual plant simulation models. } \\
\text { From the 'smart factory' perspective, the } \\
\text { RFID helps in developing communication } \\
\text { between man and machine, and within the } \\
\text { machines in a decentralized manner. This } \\
\text { eliminates the process of central planning and } \\
\text { controlling system. }\end{array}$ & $\begin{array}{l}\text { Virtualize and exchange - The model replaces } \\
\text { the physical world with the virtual world. } \\
\text { The virgin new products are replaced by } \\
\text { the remanufactured (green) products. The } \\
\text { conventional push system of production is } \\
\text { replaced by the pull system allowing mass } \\
\text { customization. This is achieved by smart } \\
\text { connected products, linking with the IoT and } \\
\text { CPS system that enables data gathering for the } \\
\text { RL. }\end{array}$ \\
\hline
\end{tabular}


- The manufacturer is assumed to be equipped with the information capabilities that provide information on the availability of respective modes of transportation at their respective terminal. We reiterate that we prioritize the sequence of transportation as the ship, train, and then the truck trailer.

- We assume the time delay due to change in uploading of computer-aided design (CAD) program for different part families on AM machine while prioritizing the FBD rules. Therefore, in this paper, the change in set-ups from one type of part family to the other is considered from the notions of change in the CAD program.

Table 3: Factors and their levels for experiments

\begin{tabular}{|c|c|c|c|}
\hline \multicolumn{4}{|l|}{ Fixed factors } \\
\hline \multirow{3}{*}{$\begin{array}{l}\text { Category } \\
\text { Price for } \\
\text { procurement per } \\
\text { unit }\end{array}$} & Variables & \multicolumn{2}{|l|}{ Value } \\
\hline & Procurement price per unit from RCY supplier (\$) & \multicolumn{2}{|l|}{100} \\
\hline & Procurement price per unit from NRM supplier (\$) & \multicolumn{2}{|l|}{200} \\
\hline $\begin{array}{l}\text { Cost of collection } \\
\text { per unit }\end{array}$ & Cost of Collection per unit for RCY supplier (\$) & \multicolumn{2}{|l|}{100} \\
\hline $\begin{array}{l}\text { Cost of } \\
\text { Production per } \\
\text { unit }\end{array}$ & Cost of Production per unit for NRM supplier (\$) & \multicolumn{2}{|l|}{200} \\
\hline \multirow{3}{*}{$\begin{array}{l}\text { Cost of holding } \\
\text { per unit }\end{array}$} & Cost of holding per unit for manufacturer $(\$)$ & \multirow{2}{*}{\multicolumn{2}{|c|}{$\begin{array}{l}0.15 \\
0.10\end{array}$}} \\
\hline & Cost of holding per unit for RCY supplier (\$) & & \\
\hline & Cost of holding per unit for NRM supplier (\$) & \multicolumn{2}{|l|}{0.20} \\
\hline \multirow{3}{*}{$\begin{array}{l}\text { Unit shortage } \\
\text { cost }\end{array}$} & Cost of unsatisfied demand per unit of manufacturer (\$) & \multicolumn{2}{|l|}{10} \\
\hline & Cost of unsatisfied demand per unit of RCY supplier (\$) & \multicolumn{2}{|l|}{5} \\
\hline & Cost of unsatisfied demand per unit of NRM supplier (\$) & \multicolumn{2}{|l|}{7.50} \\
\hline \multirow[t]{2}{*}{ Environmental } & Coefficients of innovation $(\alpha) \operatorname{Unif}\left(\alpha_{\min }, \alpha_{\max }\right)$ & \multirow{2}{*}{\multicolumn{2}{|c|}{$\begin{array}{l}(0.0001,0.01) \\
(0.1,0.4)\end{array}$}} \\
\hline & Coefficient of imitation $(\beta) \operatorname{Unif}\left(\beta_{\min }, \beta_{\max }\right)$ & & \\
\hline \multicolumn{2}{|c|}{ Taguchi Experimental design } & \multicolumn{2}{|c|}{ Levels } \\
\hline Factors & Detail of factors & 1 & 2 \\
\hline Demand & Aggregated rate of demand (units/day) $(D)$ & Expo(20) & Expo(80) \\
\hline No. of ships & Number of ships per day for the delivery to the distributor $\left(N_{s}\right)$ & 1 & 2 \\
\hline No. of trains & Number of trains per day for the delivery to the distributor $\left(N_{r}\right)$ & 1 & 3 \\
\hline \multirow[t]{3}{*}{$\begin{array}{l}\text { No. of truck } \\
\text { trailers }\end{array}$} & $\begin{array}{l}\text { Number of truck trailers per day for the delivery to the } \\
\text { distributor }\left(N_{t}\right)\end{array}$ & 1 & 4 \\
\hline & Manufacturer set-up cost $(\$)\left(K_{m}\right)$ & 10 & 15 \\
\hline & Recycled-material supplier set-up cost $(\$)\left(K_{r}\right)$ & 2 & 3 \\
\hline \multirow[t]{2}{*}{ Set-up cost } & New product raw material supplier set-up cost $(\$)\left(K_{n}\right)$ & 5 & 8 \\
\hline & $\begin{array}{l}\text { set-up cost of changing CAD program for alternate family in } \\
\text { recycling process }(\$)\left(S e_{t_{j}}\right)\end{array}$ & 2 & 4 \\
\hline \multirow[b]{2}{*}{ Environmental } & End-user market average capacity Pois $\left(\mu_{N}\right)(\mathrm{CEUM})$ & 100 & 500 \\
\hline & Per period collection investment $(\$)\left(g_{i}\right)$ & 5 & 10 \\
\hline \multirow{3}{*}{$\begin{array}{l}\text { Period for } \\
\text { information of } \\
\text { green product } \\
\text { investment }\end{array}$} & Collection investment period $\left(g_{i}\right)$ (days) (IP) & & \\
\hline & (i) Decentralized model & 10 & 15 \\
\hline & (ii) Information-sharing models & 0.5 & 2.0 \\
\hline
\end{tabular}

We considered a run of 500 time periods with 10 replications in simulation for the study which were adequate since for the given values of the variables of Bass model, the density function and cumulative function curves show the saturation values 
after a certain time. In the present paper, we assume that no products are available at each echelon of the reverse logistics model at the beginning of the simulation.

The values and the levels of the parameters considered for the simulation model mentioned in Table 3 are consistent with Dev et al. (2019). The effect of parameters such as demand rate, set-up cost, green investment, coefficients of innovation and imitation, the end-user market capacity, and the number of transportation modes available are investigated.

The Taguchi experimental design is used as a vehicle for evaluating the effect of various factors on the performances. The reader may refer to Dev et al. (2014) for a detailed explanation of the Taguchi experimental design paradigm. We have used an $\mathrm{L}_{12}$ orthogonal array for analyzing the performances. In the experimental setup, two FBD rules under three information strategies are compared, that is, in all $72(=12 \times 2 \times 3)$ simulation experiments were performed.

\subsubsection{Environmental and economic performance measures}

In addition to the environmental features complimentary to environmental performances considered by Dev et al. (2019), we consider the following characteristics related to the transportation system.

The transportation consists of two types of costs: (i) operational cost comprises of variable cost, fixed cost, and waiting charges, (ii) emission cost. We are more interested in the emission cost of the ship as the transportation via ship corresponds to green activity. Thus, for different information and FBD rules, the emission cost of the ship is compared. That is, a large number of parts are shipped through the ship if the values of emission cost related to ship are high. The emission cost of transporting the commodities from Pondicherry port to Papavov port for each mode of transportation is calculated as:

$$
\begin{aligned}
& C_{e}=d_{i j}^{m_{o}} * 100 e_{i j}^{m_{o}} * x_{i j}^{m_{o}} \\
& i \in\{p o\}, j \in\{p a\}, m_{o} \in\{M\}
\end{aligned}
$$

The economic measure includes various costs; $C_{m}, C_{r}, C_{n}$, and $C_{t}$. Manufacturer and RCY supplier costs include set-up cost (change of CAD program in case of recycled-material supplier), cost of holding, and cost of backorders. The NRM supplier costs include the cost of production, cost of set-up, cost of holding, and cost of backorders.

The cost of procurement per unit, cost of collection per unit, and cost of production per unit for the manufacturer, RCY supplier, and NRM supplier respectively are calculated as below.

In the case of the manufacturer, the procurement cost is expressed as:

$O_{i}^{j}=Q_{i}^{j} * \gamma$,

$i \in\{m\}, j \in\{r, n\}, \gamma \in\left\{p_{r}, p_{n}\right\}$.

The ordering quantity $Q_{i}^{j}$ is calculated as per the review policy described in Appendix A. A set-up cost is incurred every time the manufacturer orders.

$K_{i}^{j}=k_{i} * \delta\left(Q_{i}^{j}\right)$

$i \in\{m\}, j \in\{r, n\}$

$\delta\left(Q_{i}^{j}\right)=1$ if $Q_{i}^{j}>0,0$ otherwise

Consistent with Dev et al. (2019), the re-order point is calculated as:

$s_{i}=D \times\left(L_{i}+O I\right)+z \sqrt{\left(L_{i}+O I\right) \times\left(\sigma_{D}\right)^{2}+D^{2} \times\left(\sigma_{L i}\right)^{2}} \ldots \ldots i \in(r, n, m)$

where 
$\mathrm{z}=$ standard normal distribution parameter for stockout risk (assumed as $5 \%$ in the simulation)

OI $=$ order interval

$\sigma_{L i} \quad=$ standard deviation of lead time, and

$\sigma_{D} \quad=$ demand standard deviation

The procurement cost of suppliers is expressed as:

$O_{i}=Q_{i} * \gamma$,

$i \in\{r, n\}, \gamma \in\left\{C_{c}, P\right\}$

There are two types of set-up costs incurred in case of the recycled-material supplier; (i) a set-up cost is incurred on ordering for return products, and (ii) another set-up cost which is analogous to change in CAD program is incurred when a set-up is required to be changed from one type of part family to another on AM machine while remanufacturing. The set-up cost on ordering for returned products is similar to the manufacturer, that is,

$K_{i}=k_{i} * \delta\left(Q_{i}\right)$

$i \in\{r, n\}$

$\delta\left(Q_{i}\right)=1$ if $Q_{i}>0,0$ otherwise

Each part family requires a specific machine set-up in the form of a CAD program. This is called a major set-up. If the current set-up on the machine is for the family $j_{1}$, obviously, the set-up cost incurred only if the next part family for the remanufacturing process is $j_{2}$. In the experimental design, we consider two levels $(\$ 2$ and \$4) of set-up cost. The notion of the high value of set-up cost corresponds to the fact that the current development of AM is not fully investigated for the prompt processing of any batch size of part families. It could also present the situation when AM is compared with a traditional machine because, in any circumstances, the set-up cost of AM is comparatively lower (Pour et al., 2017). The set-up cost for the recycledmaterial supplier is calculated based on the number of times the set-up is changed for the two assumed part families, that is,

$S e_{f_{j}}=s e_{f j} * \delta\left(q_{f_{j}}\right)$

$\delta\left(q_{f_{j}}\right)=1$ if $q_{f_{j}}>0,0$ otherwise

The total operational cost of transportation involves total variable cost, total fixed cost, and total waiting charges of transportation modes. The variable cost of the commodity is calculated as:

$C_{v}=c_{i j}^{m_{o}} * x_{i j}^{m_{o}}$

$i \in\{p o\}, j \in\{p a\}, m_{o} \in\{M\}$

The fixed cost is calculated as:

$C_{F}=f_{i j}^{m_{o}} * y_{i j}^{m_{o}}$

$i \in\{p o\}, j \in\{p a\}, m_{o} \in\{M\}$

The waiting charges of the respective modes of transportation are calculated as:

$C_{w}=\sum_{k=1}^{t} t_{w_{i j}}^{m_{o}}(t-k) * c_{w_{i j}}^{m_{o}}$

$k=1,2,3, \ldots \ldots t$

$i \in\{p o\}, j \in\{p a\}, m_{o} \in\{M\}$

where, $t$ is the time at which mode of transport is ready for transportation.

The cost of holding for each echelon is computed as:

$H_{i}=I_{i} * h_{i}$

where

$I_{i}=$ On-hand inventory, and 
$h_{i}=$ holding cost per period

$i \in(r, n, m)$

\section{Results and discussions}

\subsection{Environmental and Economic performances}

For the two FBD rules (FCFAM and MAS), the maximum and minimum cost values corresponding to environmental and economic performances, respectively are reported from the 72 simulation experiments. The two FBD rules are analyzed for three information scenarios, namely (i) decentralized, (ii) recycled-material supplier information (RCYINF) and, (iii) manufacturer information (MNFINF).

We report the results concerning the three information cases with two FBD rules in Table B.1. The results reported in Table B.1 of Appendix B, are values attained through simulation experiments at optimal levels (i.e. levels of additivity test verification) for each factor using the Taguchi procedure.

In Table B.1 of Appendix B, column IV shows the maximum of the maximum value of each informational scenario for the respective FBD rules. For instance, RCYINF has the maximum value $(=2641300)$ for $\left(O_{m}^{r}\right)$ under FCFAM rule. Accordingly, Table B.1 (column V) represents the minimum of maximum values. Subsequently, Table B.1 (last column) demonstrates the enhancement in environmental performance related to each measure. Similarly, under each information scenario for two cases of FBD rules, economic performance related to different measures with minimum values are reported in Table B.1.

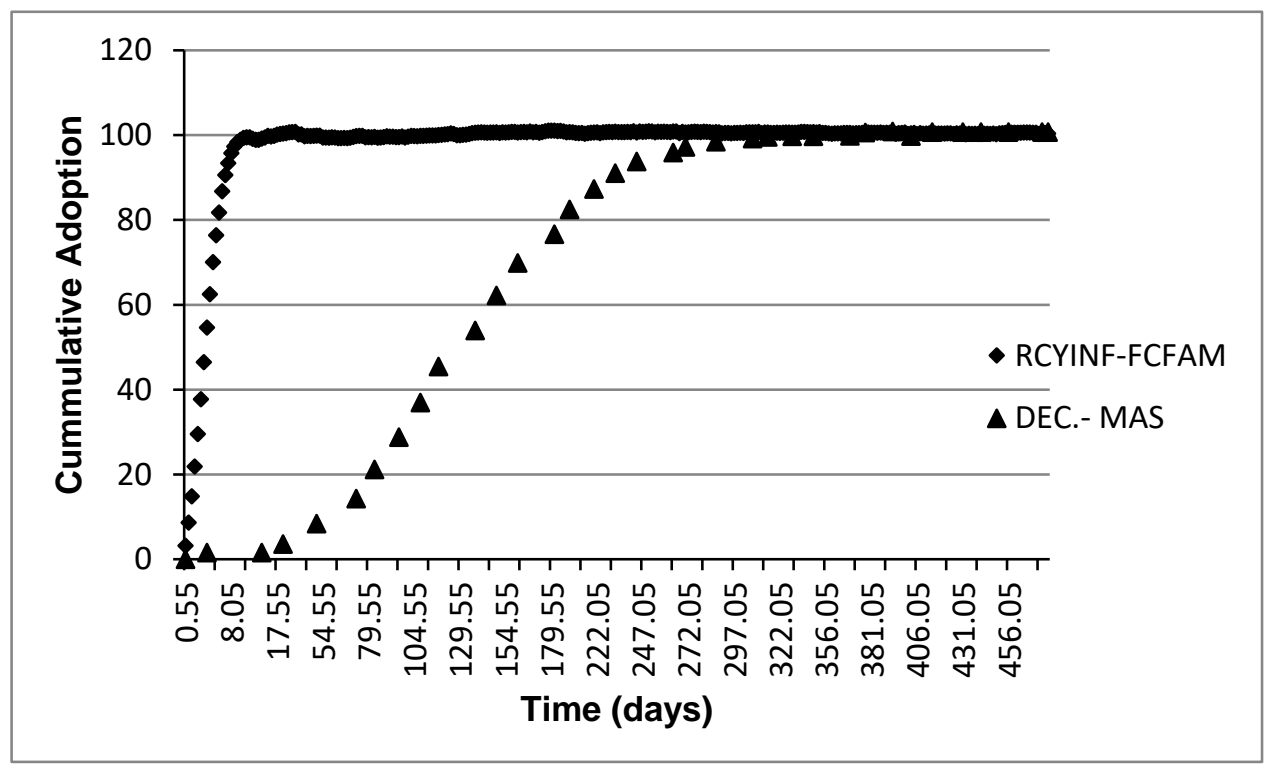

Figure 2: Comparison of Cumulative adoption of RCYINF-FCFAM and DecentralizedMAS policies

The value of total environmental cost in the case of RCYINF related to FCFAM is found the largest. This shows that the RCYINF information strategy outperforms in delivering a maximum number of recycled parts to the manufacturer and in turn to the distributor. Moreover, it is found that the recycled-material supplier made maximum total promotional investments viá RCYINF information strategy. Since the maximum values of RCYINF correspond to the FCFAM priority rule of dispatching, henceforth, 
we denote this combination of information-sharing and FBD rule as 'RCYINFFCFAM'. The results illustrate that information-sharing between the Bass model and the inventory system of the RCY supplier shows a considerable increase in each of the parameters $\left(O_{m}^{r}=10.2, O_{r}=10.1\right.$, and $\left.G_{r}=32.5\right)$ corresponding to the environmental performance by adopting appropriate information and FBD rule (Table B.1). Further, it is seen that the value of emission cost related to ship transportation is maximum in the RCYINF-FCFAM case. The result shows that the larger number of transactions is made through the ship, indicating a considerable tendency towards the green practice. The above findings provide solution to the research question (i) and (ii) mentioned in Section 1.2, in which we positioned this research to focus on the synergy of I4.0 and $\mathrm{CE}$, while simultaneously analyzing the effect of integration of innovation in terms of diffusion of green products and I\&PP policy on environmental performance in terms of $\mathrm{CO}_{2}$ emission.

Figure 2 shows a comparison of the cumulative adoption of green products for RCYINF-FCFAM and Decentralized-MAS policies. The reason for the larger number of transactions through the ship is straight forward and can be explained by the fact that the adoption rate increases rapidly much earlier in the case of RCYINF-FCFAM which results in a larger number of transactions through the ship. We reiterate that we have assumed the sequence of transportation modes in order as ship, train, and truck.

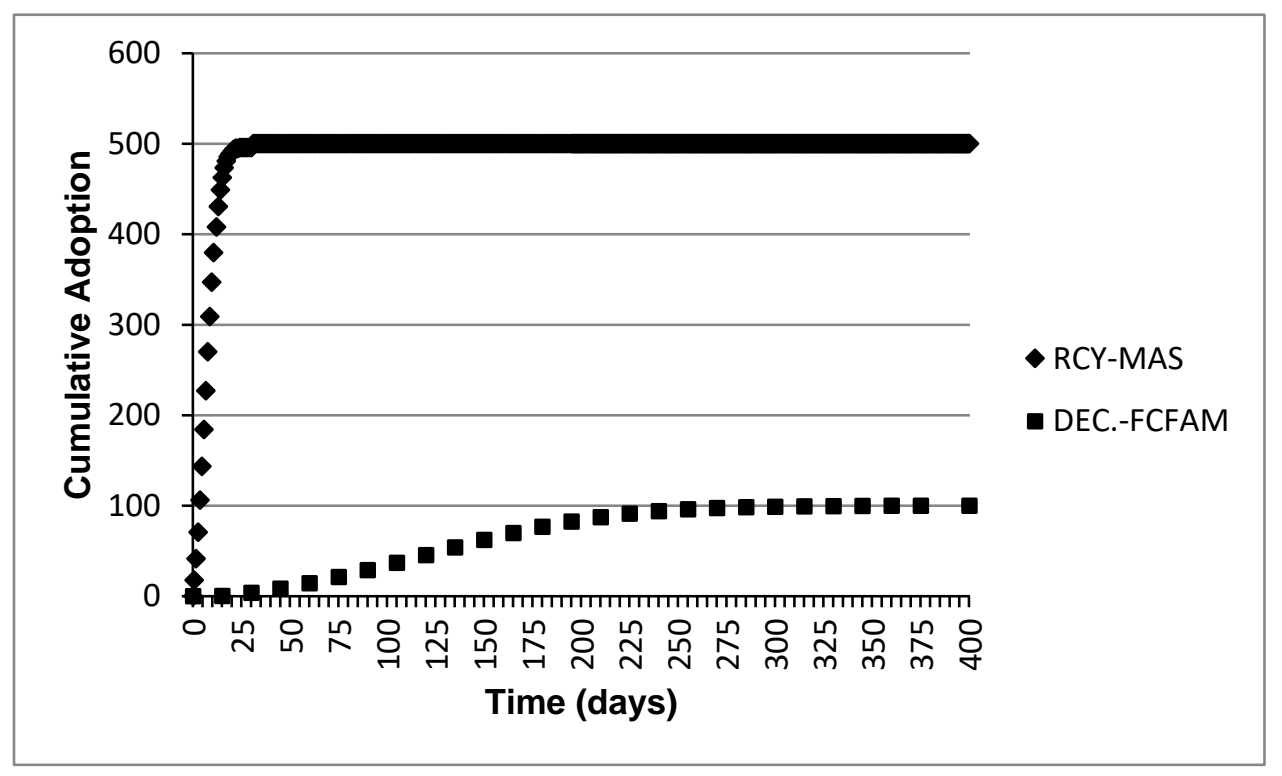

Figure 3: Comparison of Cumulative adoption of RCYINF-MAS and DecentralizedFCFAM policies for the total transportation operational cost performance

We discuss now, the results related to economic performance. As the focus of this study is to study the impact of alternate FBD rules on the case based transportation network system, we discuss the two related economic performances: total transportation operational cost and total set-up cost affected by the change in FBD rule at recycledmaterial supplier end. From Table B.1, the joint strategy of information and FBD rule that should minimize the economic performance for the total transportation operational cost is the combination Decentralized-FCFAM. The result can be explained in Figure 3, which shows that there is a gradual increase in the adoption of green products in the case of Decentralized-FCFAM policy due to which the value of operational cost is less. From Table B.1, it can be seen that there is a $69 \%$ improvement in economic 
performance when adopting the Decentralized-FCFAM combination. It is seen in Table B. 2 of Appendix B that the optimal level of set-up cost corresponding to AM $\left(S_{e t} 1\right)$ shows its potential vis-à-vis traditional remanufacturing. As shown in Table B.1, the waiting time cost of the ship for the case RCYINF-MAS has a minimum value. The result can be explained from Figure 3 which shows the adoption of green products with a larger end-user market capacity $(\mathrm{CEUM}=500)$ in the early period allows quicker remanufacturing. Further, the MAS dispatching rule outperforms FCFAM. Thus, the above findings provide the solution to the research question (iii) mentioned in Section 1.2 , in which we positioned this research to focus on the speed with which the products are fed to the shipping terminal by adopting the appropriate information-sharing and FBD rule.

Similarly, in the case of the total set-up cost incurred due to change from one type of FBD rule to the other, we find that the combination MNFINF-MAS minimizes the economic performance. This can be explained in Figure 4, which shows the early adoption of green products stabilizes the number of set-ups of the machine in the initial time periods. The result is also consistent with the literature that MAS priority rule results in a lesser number of setups (Nomden et al., 2008). Therefore, the adoption of MNFINF-MAS can be a useful policy when set-up cost during the recycling process is significantly high (e.g. in the recycling process of the present case of the refrigerator with large variants). From Table B.1, it can be seen that there is an $88.7 \%$ improvement in economic performance with the combination of MNFINF-MAS. Our findings show that adopting appropriate FBD rule and information-sharing strategy provides the potential to enhance the environmental and economic performances in I4.0 and RL oriented ReSOLVE environment.

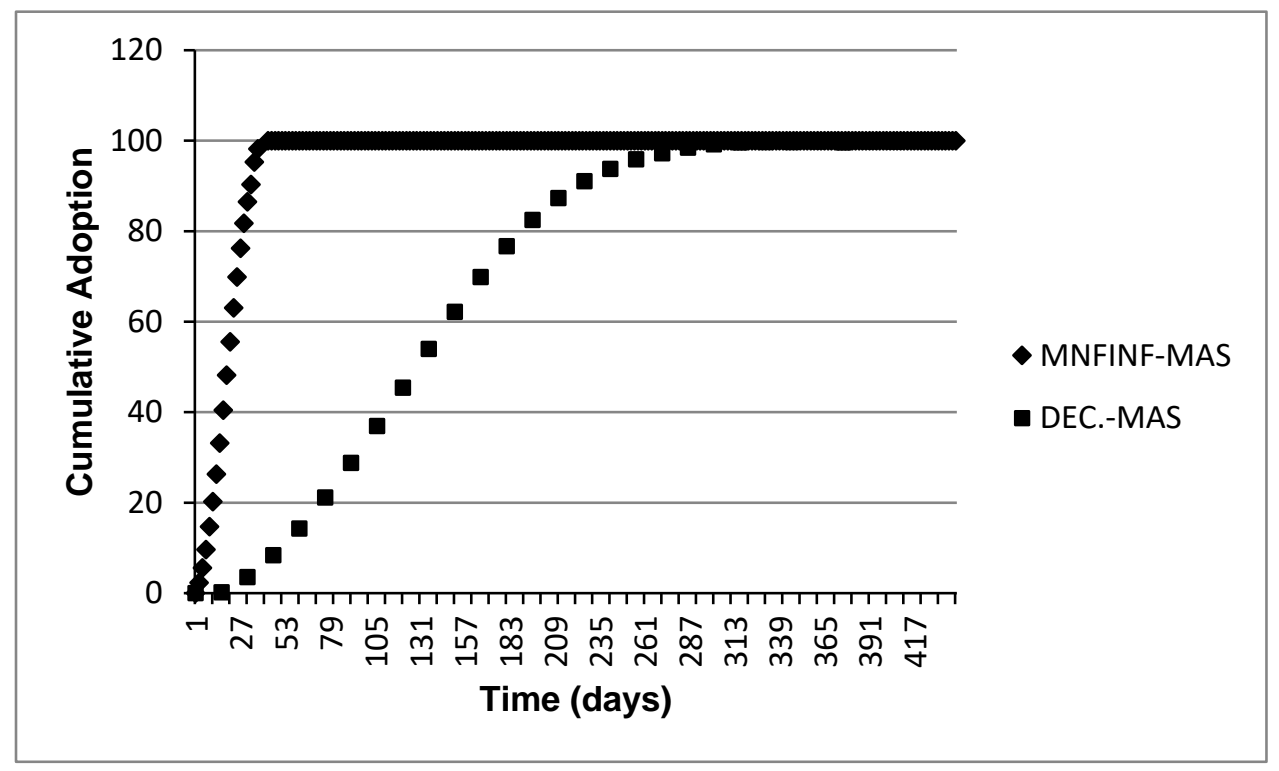

Figure 4: Comparison of Cumulative adoption of MNFINF-MAS and DecentralizedMAS strategies for the total set-up cost incurred due to change in FBD rule

Figures 2, Figure 3, and Figure 4 show the quick adoption curves corresponding to the information-sharing mechanisms (RCYINF and MNFINF) of the model. The reason can be described as the results due to real-time information on inventory levels allows higher frequency of orders which subsequently result in quickly achieving the 
maximum adoption. This is consistent with the property of the Bass model (Equation (2)) which shows that faster rate of promotional investment would result achieving maximum value of adoption very soon and would become constant when the value of $x(t)$ is equal to the capacity of the end-user market $(N)$. For the optimal environmental and economic results under the appropriate FBD rule and information-sharing strategies, we provide practical implications in the next section.

\subsection{Practical implications of mathematical model}

The optimal levels for RCYINF-FCFAM strategy for the environmental performance, Decentralized-FCFAM strategy for the total transportation operational cost performance, and MNFINF-MAS strategy for the total set-up cost incurred due to change in FBD rule are shown in Table B.2 of Appendix B. ANOVA is conducted to estimate the error variance for the factor effects and the variance of the prediction error, which also provide necessary input for justifying the additivity assumption. Table B.2 also shows the ANOVA results corresponding to the above strategy. In Table B.2, the ANOVA test shows the significant factors that affect the RCYINF-FCFAM, Decentralized-FCFAM, and MNFINF-MAS strategies corresponding to environmental and economic performances. Further, whereas the optimum levels in case of RCYINFFCFAM are $D 1, N_{s} 2, N_{r} 1, N_{t} 1, K_{m} 1, K_{r} 1, K_{n} 2, S_{e t} 1, C E U M 1, I P 1$, and $C I 2$ (i.e., the levels are 2111222122221 ), the optimum levels in case of Decentralized-FCFAM are $D 1, N_{s} 1, N_{r} 2, N_{t} 2, K_{m} 2, K_{r} 1, K_{n} 1, S_{e t} 1, C E U M 1, I P 2$, and $C I 2$ (i.e., the levels are 11 $\begin{array}{llllllll}2 & 2 & 1 & 1 & 1 & 1 & 2 & 2\end{array}$ ), and the optimum levels in case of MNFINF-MAS are $D 1, N_{s} 2, N_{r} 1$, $N_{t} 1, K_{m} 2, K_{\mathrm{r}} 2, K_{n} 1, S_{e t} 1, C E U M 1, I P 2$, and $C I 1$.

The additivity test was carried out in all the above cases. The additivity test values for RCYINF-FCFAM, Decentralized-FCFAM, and MNFINF-MAS are summarized in Table B.3 of Appendix B. Since, the prediction error (column 6 of Table B.3) is found to be within the 2-standard deviation confidence limits (column 8 of Table B.3) in all the three cases, it confirms the additivity assumption.

\section{Conclusions}

The present paper proposes operational excellence in terms of integration between I4.0 informational technologies and RL oriented CE represented by the ReSOLVE model. The present study proposes to visualize an arrangement of an RFID-enabled and cloudbased ERP system that enables computing product returns with the inbuilt Bass model algorithm module. The present study explores the extensive simulation of reverse logistics that corroborates to the virtual factory component of I4.0. Taguchi's experimental design framework provides a constructive feature in I4.0 real-time system environment for fast execution.

\subsection{Implications of research}

The present study provides a theoretical as well as a practical framework for the operational excellence issues under the umbrella of Integrated I4.0 and the CE. Theoretically, the relationship between principles of I4.0 and CE is established in the context of operations management of a reverse logistics system that supports the research agenda suggested by Jabbour et al. (2018) in the context of resource-based theory. Jabbour et al. (2018) suggested underpinning CE strategies by exploiting the resource capabilities of I4.0 in the form of sharing of information.

From the findings, we can infer that the implementation of technology characteristics of operational excellence in terms of I4.0, reverse logistics, and lean approach suggested by Mangla et al. (2019) provides valuable guidance to practice for 
the sustainable performances of a circular SC. The present study also supports the performance dimensions of operational excellence identified by Mangla et al. (2019) and full circularity adoption suggested by Urbinati et al. (2017). The full circularity adoption is captured by implementing the diffusion of innovation at the distribution end, and involvement of recycled-material supplier at the upstream end in terms of collaboration in information-sharing, transparency in product returns and flexibility in process scheduling viá different FBD rules in a reverse supply chain. To the best of our knowledge, this is one of the first research studies to provide valuable insights for full circularity adoption for sustainable operations management viá I\&PP, AM set-up, FBD rules, and transportation system of the reverse logistics.

We propose that the managers need to consider a load of remanufacturing/recycling shop by considering the integration of the market aspect of diffusion of innovation of green products to the operations management of the reverse logistics system. Further, the present research supports the suggestion of Jakhar et al. (2018) that the managers should look at the performance of the entire SC while implementing lean practices including emissions of the alternate mode of transportation.

The environmental regulations in some industries pose an additional cost to the organization. This is mainly relevant to those industries where the share of environmental costs in total manufacturing cost is significantly higher (Wagner et al., 2001). Economic benefits monotonously fall with the enhancement in environmental performance (Wagner and Schaltegger, 2003). Along these lines, Luthra and Mangla (2018b) have also pointed out that the economic aspect of the implementation of I4.0 should carefully be studied. The present study provides such leverage to a manager that can extend the period of economic benefit by adopting a suitable information-sharing strategy and scheduling policy. For instance, as seen in the RCYINF-MAS strategy, the backorders are reduced due to the high value of end-user market capacity and thereby reduces the value of the cost of total inventory $(=887.4196)$. However, this performance is achieved at the expense of a suitable promotional investment value.

In certain cases when the companies are not in the situation to establish technological capabilities of I4.0 or might be uncertain about entering into reverse logistics systems, especially in the early periods of their business, we propose that even the information related to decentralized strategy also plays an important role. For instance, from Figure 3, we find that given the low value of the end-user market capacity at the initial stage; a low economic performance in the Decentralized-FCFAM strategy is observed.

\subsection{Limitations and future research directions}

The results obtained in the present research are context-specific and deserve a more detailed analysis in terms of parameterization and SC network structures for generalization. From the social aspect, the present study contributes to exploring consumers' behavior by integrating I4.0 technology through a cloud-based ERP system equipped with the Bass model algorithm.

The present study can be extended towards dealing with multiple suppliers instead of one supplier (as considered in our case). However, dealing with multiple suppliers would involve frequent orders from manufacturer resulting in high operational costs. This is similar to the situation when the system is operating for information-based MNFINF-MAS strategy in which we find that although the adoption of green products are quick (Figure 4), the value of manufacturer's ordering cost with recycled-material supplier $(=\$ 630)$ is comparatively high for economic performance (Table B.1 of Appendix B). Thus, the situation warrants the company to move all the suppliers to a 
cloud ERP as a common platform. This is consistent with Kenandy's (Kenandy, 2019) cloud-based open cyber-physical-social network (CPSS) platform that suggests a social network viá interaction of cross-terminal applications of planning, scheduling, social computing, etc., with the cyber-physical networks built under I4.0 environment (Jiang et al., 2016).

The above-mentioned system of moving the several suppliers to a CPSS platform will diminish the operational cost in the trade-off with the investments made for promotions of green products (collection investment in our case). However, for the increasing values of promotional cost, the operational cost might exceed due to a large number of suppliers moving to the cloud-based system. This is the situation similar to the high cost of the total inventory of the manufacturer in case of information-based MNFINF-MAS strategy (=\$29715.62) for economic performance (Table B.1 of Appendix B). Therefore, in spite of the availability of CPSS-based I4.0 capabilities, the manager should look at the "optimum" promotional investment that allows moving the multiple suppliers to the cloud-based CPSS system as a common platform. This could be an important future research work. Another issue for future work may involve the environmental and economic performances considering the effect of disposal of returns. The study concerning ripple effect (i.e. disturbance that spreads from upstream towards downstream affecting SC output) for sustainable performances in reverse logistics could be another interesting issue for future research.

\section{Acknowledgment}

One of the co-authors of this paper would like to acknowledge the funding support received through University Grant Commission, New Delhi, India. Grant No.: F.18411/2017(IC) under UGC-UKIERI Joint Research Programme (UKIERI-III) on a research project on "Advance Analytics for Green and Resilient Supply Chain Decision Making".

\section{References}

Abdul-Rashid, S., Sakundarini, N., Raja Ghazilla, R.A., Ramayah, T., 2017. The impact of sustainable manufacturing practices on sustainability performance: empirical evidence from Malaysia. Int. J. Oper. Prod. Manag. 37 (2), 182-204.

Ahmadov, Y., Helo, P., 2016. A cloud-based job sequencing with sequence-dependent setup for sheet metal manufacturing. Ann. Oper. Res. 270(1), 1-20.

Akçali, E., Çetinkaya, S., 2011. Quantitative models for inventory and production planning in closed-loop supply chain. Int. J. Prod. Res. 49(8), 2373-2407.

Alayón, C., Säfsten, K., Johansson, G., 2017. Conceptual sustainable production principles in practice: do they reflect what companies do? J. Clean. Prod. 141, 693701.

AMEYA Logistics 2019. Ameya logistics Pvt Ltd. Container Freight Station Tariff. http://www.ameyalogistics.com/images/Ameya_Tariff.pdf (accessed 10 January 2019).

Amini, M., Li, H., 2015. The impact of dual-market on supply chain configuration for new products. Int. J. Prod. Res. 53(18), 5669-5684.

APM Terminals 2019. APM Terminals Pipavav. https://www.apmterminals.com/en/ operations/asia-pacific/pipavav (accessed 10 January 2019).

Atasu, A., Guide Jr., V.D.R., Wassenhove, L.N.V., 2008. Product reuse economics in closed-loop supply chain research. Prod. Oper. Manage. 17(5), 483-496. 
Bass, F.M. 1969. A new product growth model for consumer durable. Manage. Sci. $15(5), 215-227$.

Bektaş, T., Crainic, T.G., 2007. A Brief Overview of Intermodal Transportation: Logistics Engineering Handbook. CRC Press, Boca Raton.

Chukwuekwe, D., Schjølberg, P., Rødseth, H., Stuber, A., 2016. Reliable, robust and resilient systems: towards development of a predictive maintenance concept within the industry 4.0 environment. Proceedings of EFNMS Euro Maintenance Conference, May 30 - June 2, Athens, Greece.

CONCOR 2017. Container Corporation of India. http://www.concorindia.com/trace/ terminal/tariff/Tar1155Publictariff15082018.pdf (accessed 10 January 2019).

Department of Transport. 2017. Transport statistics Great Britain 2017. Tech. Rep., London.

Dev, N.K., Shankar, R., Swami, S., 2019. Difussion of green products in Industry 4.0: Reverse logistics issues during design of inventory and production planning system. Int. J. Prod. Econ. https://doi.org/10.1016/j.ijpe.2019.107519.

Dev, N.K., Shankar, R., Choudhary, A., 2017. Strategic design for inventory and production planning in closed-loop hybrid system. Int. J. Prod. Econ. 183, 345-353.

Dev, N.K., Shankar, R., Dey, P.K., Gunasekaran, A., 2014. Holonic supply chain: a study from family-based manufacturing perspective. Comput. Ind. Eng. 78, 1-11.

Despeisse, M., Baumers, M., Brown, P., Charnley, F., Ford, S. J., Garmulewicz, A., et al. (2017). Unlocking value for a circular economy through 3D printing: A research agenda. Techno. Forecast. Soc. Chan. 115, 75-84.

Dubey, R., Gunasekaran, A., Papadopoulos, T., Childe, S.J., Shibin, K.T., Wamba, S.F., 2017. Sustainable supply chain management: framework and further research directions. J. Clean. Prod. 142, 1119-1130.

Elkington, J., 1994. Towards the Sustainable Corporation: Win-Win-Win Business Strategies for Sustainable Development. Calif. Manage. Rev. 36(2), 90-100.

Fettermann, D.C., Gobbo Sá Cavalcante, C., Domingues de Almeida, T., Tortorella, G.L., 2018. How does Industry 4.0 contribute to operations management? J. Ind. Prod. Eng. 35(4), 255-268.

Flapper, S.D.P., Fransoo, J.C., Broekmeulen, R.A.C.M., Inderfurth, K., 2002. Planning and control of rework in the process industries: a review. Prod. Plan. Control 13(1), 26-34.

Ford, S., Despeisse, M., 2016. Additive manufacturing and sustainability: an exploratory study of the advantages and challenges. J. Clean. Prod. 137, 1573-1587.

Ganzha, M., Paprzycki, M., Pawlowski, W., Szmeja, P., Wasielewska, K., 2016. Semantic interoperability in the internet of things: an overview from the inter-IoT perspective. J. Net. Comput. App. 81, 111-124.

Ghisellini, P., Cialani, C., Ulgiati, S., 2016. A review on circular economy: The expected transition to a balanced interplay of environmental and economic systems. J. Clean. Prod. 114, 11-32.

González-Benito, J., González-Benito, Ó., 2006. A review of determinant factors of environmental proactivity. Bus. Strateg. Environ. 15 (2), 87-102.

Guarnieri, P., e Silva, L.C., Levino, N.A., 2016. Analysis of electronic waste reverse logistics decisions using strategic options development analysis methodology: a Brazilian case. J. Clean. Prod. 133, 1105-1117.

Guide Jr., V.D.R., 2000. Production planning and control for remanufacturing: industry practice and research needs. J. Oper. Manage. 18, 467-483.

Gunasekaran, A., Irani, Z., 2014. Sustainable operations management: design, modelling and analysis. J. Oper. Res. 65(6), 801-805. 
Gunasekaran, A., Irani, Z., Papadopoulos, T., 2014. Modelling and analysis of sustainable operations management: Certain investigations for research and applications. J. Oper. Res. Soc. 65(6), 806-823.

Hermann, M., Pentek, T., Otto, B., 2016.Design principles for industry 4.0 scenarios. Proceedings of the $49^{\text {th }}$ Hawaii International Conference on System Sciences. pp. 3928-3937.

Hofmann, E., Rüsch, M., 2017. Industry 4.0 and the current status as well as future prospects on logistics. Comp. Indust. 89, 23-34.

Holmström, J., Romme, A.G.L., 2012. Five steps towards exploring the future of operations management. Oper. Manage Res. 5(1-2), 37-42.

Huang, S.H., Liu, P., Mokasdar, A., Hou, L., 2013. Additive manufacturing and its societal impact: a literature review. Int. J. Adv. Manuf. Technol. 67, 1191-1203.

Jabbour de Sousa, A.B.L., Jabbour, C.J.C., Filho, M.G., Roubaud, D., 2018. Industry 4.0 and the circular economy: a proposed research agenda and original roadmap for sustainable operations. Ann. Oper. Res. 270(1-2), 273-286.

Jabbour, C.J.C., Jabbour de Sousa, A.B.L., Sarkis, J., Filho, M.G., 2017. Unlocking the circular economy through new business models based on large-scale data: an integrative framework and research agenda. Technol. Forecast. Soc. Chang. http://dx.doi.org/10.1016/j.techfore.2017.09.010.

Jakhar, S.K., Rathore, H., Mangla, S.K., 2018. Is lean synergistic with sustainable supply chain? An empirical investigation from emerging economy. Resour. Conserv. Recycl. 139, 262-269.

Jiang, P., Ding, K., Leng, J., 2016. Towards a cyber-physical-social-connected and service-oriented manufacturing paradigm: Social Manufacturing. Manuf. Letters 7, $15-21$.

Kagermann, H., Lukas, W., Wahlster, W., 2011. Industrie 4.0: with the internet of things on the way to the $4^{\text {th }}$ Indudtrialrevolution. VDI Nachrichten, Berlin.

Karmeshu, Baliga, P., Shah, J., Swami, S., 2011.Concentrated promotional efforts and product diffusion: a normative analysis. Tech. Oper. Manage. 2(2), 90-101.

Kenandy, 2019. Cloud ERP Evaluation Guide for Manufacturers. http://www.kenandy.com/ (accessed 10 September 2019).

Kim, H.J., Lee, D.H., Xirouchakis, P., 2007. Disassembly scheduling: literature review and future research directions. Int. J. Prod. Res. 45(18-19), 4465-4484.

Kirchherr, J., Reike, D., Hekkert, M., 2017. Conceptualizing the circular economy: an analysis of 114 definitions. Resour. Conserv. Recycl. 127, 221-232.

Kirchherr, J., Piscicellia, L., Bour, R., Kostense-Smit, E., Muller, J., HuibrechtseTruijens, A., Hekkert, M., 2018. Barriers to the circular economy: evidence from the European Union (EU). Ecolog. Econ. 150, 264-272.

Kleindorfer, P.R., Singhal, K., Wassenhove, L.N., 2005. Sustainable operations management. Prod. Oper. Manage. 14(4), 482-492.

Kumar, A., Rahman, S., 2014. RFID-enabled process reengineering of closed-loop supply chains in the health care industry of Singapore. J. Clean. Prod. 382-394.

Luthra, S., Mangla, S.K., 2018a. Evaluating challenges to industry 4.0 initiatives for supply chain sustainability in emerging economies. Process Safe. Env. Protec. 117, $168-179$.

Luthra, S., Mangla, S.K., 2018b. When strategies matter: adoption of sustainable supply chain management practices in an emerging economy's context. Resour. Conserv. Recycl. 138, 194-206.

MacArthur, D.E., Zumwinkel, K., Stuchtey, M.R., 2015. Growth within: A circular economy vision for a competitive Europe. Report of Ellen MacArthur Foundation. 
Matsumoto, M., Yang, S., Martinsen, K., Kainuma, Y., 2016. Trends and research challenges in remanufacturing. Int. J. Precis. Eng. Manufact. Green Technol. 3(1), 129-142.

McDowall, W., Geng, Y., Huang, B., Barteková, E., Bleischwitz, R., Türkeli, S., Doménech, T., 2017. Circular economy policies in China and Europe. J. Ind. Ecolo. 21(3), 651-661.

Mangla, S.K., Kusi-Sarpong, S., Luthra, S., Bai, C., Jakhar, S.K., Khan, S.A., 2019. Operational excellence for improving sustainable supply chain performance. Resour. Conserv. Recycl. 142, 277-278.

Nomden, G., van Der Zee, D.J., Slomp, J., 2008. Family-based dispatching: anticipating future jobs. Int. J. Prod. Res. 46(1), 73-97.

Olson, E.L., 2013. Perspective: The Green Innovation Value Chain: A Tool for Evaluating the Diffusion Prospects of Green Products. J. Prod. Innov. Manage. 30(4), 782-793.

Park, D., Kim, N.S., Park, H., Kim, K., 2012. Estimating Trade-off among Logistics Cost, $\mathrm{CO}_{2}$ and Time: A Case Study of Container Transportation Systems in Korea. Int. J. Urban Sci. 16(1), 85-98.

Pour, M.A., Zanoni, S., Bacchetti, A., Zanardini, M., Perona, M., 2017. Additivity manufacturing impacts on a two-level supply chain. Int. J. Syst. Sc. Oper. Logist. 6(1), 1-14.

Qu, Y., Bektaş, T., Bennell, J., 2016. Sustainability SI: Multimode multicommodity network design model for intermodal freight transportation with transfer and emission costs. Networ. Spatial Econ. 16(1), 303-329.

Reike, D., Vermeulen, W.J.V., Witjes, S., 2018. The circular economy: New or Refurbished as CE 3.0? - Exploring controversies in the conceptualization of the circular economy through a focus on history and resource value retention options. Resour. Conserv. Recycl. 135, 246-264.

Rogers, E.M., 2003. Diffusion of Innovations. Free Press, New York.

Rymaszewska, A., Helo, P., Gunasekaran, A., 2017. IoT powered servitization of manufacturing: An exploratory case study. Int. J. Prod. Econo. 192, 92-105.

Savaskan, R.C., van Wassenhove, L.N., 2006. Reverse channel design: the case of competing retailer. Manage. Sci. 52(1), 1-14.

Schramm, M.E., Trainor, K.J., Shanker, M., Hu, M.Y., 2010. An agent-based diffusion model with consumer and brand agents. Decis. Support Syst. 50(1), 234-242.

Sehnem, S., Chiappetta Jabbour, C.J., Farias Pereira, S.C., de Sousa Jabbour, A.B.L., 2019. Improving sustainable supply chains perfromance through operational excellence: circular economy approach. Resour. Conserv. Recycl. 149, 236-248.

Singh, A., Mishra, N., Ali, S.I., Shukla, N., Shankar, R., 2015. Cloud computing technology: reducing carbon footprint in beef supply chain. Int. J. Prod. Econ. 164, 462-471.

Souza, G.C., 2013. Closed-loop supply chains: A critical review, and future research. Dec. Sci. 44(1), 7-38.

Stock, T., Seliger, G., 2016. Opportunities of sustainable manufacturing in Industry 4.0. Procedia Cirp 40, 536-541.

Stock, T., Obenaus, M, Kunz, S., Kohl, H., 2018. Industry 4.0 as enabler for a sustainable development: A qualitative assessment of its ecological and social potential. Proc. Safe. Environ. Protec. 118, 254-267.

Sun, Y., Yan, H., Lu, C., Bie, R., Thomas, P., 2012. A holistic approach to visualizing business models for the internet of things. Commun. Mob. Comput. 1, 1-7. 
Tibben-Lembke, R.S., Rogers, D.S., 2002. Differences between forward and reverse logistics in a retail environment. Supply Chain Manage. Int. J. 7(5), 271-282.

Tortorella, G.L., Fettermann, D., 2018. Implementation of industry 4.0 and lean production in Brazilian manufacturing companies. Int. J. Prod. Res. 56(8), 29752987.

Urbinati, A., Chiaroni, D., Chiesa, V., 2017. Towards a new taxonomy of circular economy business models. J. Clean. Prod. 168, 487-498.

Vanderroost, M., Ragaert, P., Verwaeren, J., De Meulenaer, B., De Baets, B., Devlieghere, F., 2017. The digitization of a food package's life cycle: Existing and emerging computer systems in the pre-logistics phase. Comp. Indus. 87, 15-30.

Wagner, M., Schaltegger, S., 2003. How does sustainability performance relate to business competitiveness? Greener Manage. Int. 44, 5-16.

Wagner, M., Schaltegger, S., Wehrmeyer, W., 2001. The relationship between the environmental and economic performance of firms: what does theory propose and what does empirical evidence tell us? Greener Manage. Int. 34, 95-108.

Wang, W., Wang, Y., Mo, D., Tseng, M.M., 2017. Managing component reuse in remanufacturing under product diffusion dynamics. Int. J. Prod. Econ. 183, 551560.

Wei, S., Tang, O., Sundin, E., 2015. Core (product) acquisition management for remanufacturing: a review. J. Remanu. 5(1), 1-27.

Yu, C., Xu, X., Lu, Y., 2015. Computer-integrated manufacturing, cyber-physical systems and cloud manufacturing: Concepts and relationships. Manuf. Lett. 6, 5-9.

Zhao, S., Zhu, Q., 2015. Remanufacturing supply chain coordination under the stochastic remanufacturability rate and the random demand. Ann. Oper. Res. 257(12), 661-695.

Zhong, R.Y., Xu, X., Klotz, E., Newman, S.T., 2017. Intelligent manufacturing in the context of Industry 4.0: A review. Eng. 3(5), 616-630. 


\section{Appendix A}

\section{Notations}

Consistent with Dev et al. (2019), the following notations for the indexes, variables and parameters are used in our model.

\section{Indexes}

$r$

$n$

$m$

po

pa

EUM

$\mathrm{M}$

\section{Cost variables}

$h_{i}, i \in(r, n, m)$

$k_{i}, i \in(r, n, m)$

$p_{i}, i \in(r, n)$

$C_{c}$

$C_{i}, i \in(r, n, m)$

$H_{i}, i \in(r, n, m)$

$K_{i}^{j}, i \in(m), j \in(n)$

$K_{i}, i \in(n)$

$s e_{f_{j}}$

$S e_{f_{j}}$

$O_{i}^{j}, i \in(m), j \in(r, n)$

$O_{i}, i \in(r, n)$

$P$

$c_{i j}^{m_{o}}$

$f_{i j}^{m_{o}}$

$e_{i j}^{m_{o}}$

\section{Parameters}

$s_{i}, i \in(r, n, m)$

$D=\operatorname{Expo}\left(\mu_{D}\right)$

$L_{i}, i \in(r, n, m)$

$Q_{i}^{j}, i \in(m), j \in(r, n)$

$Q_{i}, i \in(r, n)$

$S_{i}, i \in(r, n, m)$

$I_{i}, i \in(r, n, m)$

$X_{i}^{t}, i \in(r, n, m)$

$G_{i}, i \in(r)$ recycled-material supplier

new-raw-material supplier

manufacturer

Pondicherry port

Papavov, Gujrat port

end-user market

set of modes of transportation

cost of $i$ for holding per unit

cost of $i$ per order for the set-up

price of procurement per unit from $i$ for the manufacturer

cost of collection per unit

total cost of $i$

total cost of $i$ for holding

total cost of set-up of $i$ ordered from $j$

total cost of set-up of $i$

cost for changing the set-up of family $f_{j}$, where $f_{j} \in(1 \& 2)$

Total set-up cost per period for changing from one family to the other family of $f_{j}$

total cost of ordering of $i$ ordered from $j$

total cost of ordering of $i$

cost of production per unit

variable cost per unit to ship the commodities from terminal $i$ to $j$ via' mode $m_{o} \in(M)$

fixed cost per batch for shipping the commodities from terminal $i$ to $j$ via' mode $m_{o} \in(M)$

emission cost for transfering the commodities from terminal $i$ to $j$ viá mode $m_{o} \in(M)$

re-order point of $i$

demand following an exponential process

lead times of $i$

order quantity of $i$ ordered to $j$

order quantity of $i$

order-up-to level of $i$

inventory on-hand of $i$

position of inventory of $i$ at time $t$

total investment made by $i$ for green products 
$x_{i j}^{m_{o}}$

$y_{i j}^{m_{o}}$

$d_{i j}^{m_{o}}$

$n_{t_{i j}}^{m_{o}}$

$t_{w_{i j}}^{m_{o}}$

Number of products transported from terminal $i$ to $j$ viá mode $m_{o} \in(M)$

Number of batches unloaded for shipping the commodities from terminal $i$ to $j$ viá mode $m_{o} \in(M)$

distance covered from the terminal $i$ to $j$ by the mode $m_{o} \in(M)$

Number of commodities loaded on mode per shipment from terminal $i$ to $j$ viá mode $m_{o} \in(M)$

waiting time of mode $m_{o} \in(M)$ at the terminal for transporting the commodities from $i$ to $j$

Manufacturer's Periodic review policy

Consistent with Dev et al. (2019), the policy is described by $S_{n}^{t}$ and $S_{r}^{t}$. Here the value of $\mathrm{R}$ based on Bass model represents order-up-to level of RCY supplier (i.e. $S_{r}^{t}=R$ in this case). The superscript $t$ represents the beginning of the period. Upon review in period $t$,

$$
\text { if } X_{n}^{t}+X^{t}{ }_{r}<S_{m}^{t} \text {; }
$$

An order of size $\left(S_{m}^{t}-\left(X_{n}^{t}+X^{t}\right)\right)$ to NRM supplier and $X^{t} r$ to the RCY supplier is released by the manufacturer.

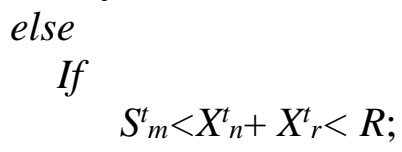

An order of size $X^{t} r$ is released to RCY supplier by the manufacturer. 
Appendix B

Table B.1: Environmental and Economic performances for two FBD rules under each information-sharing strategy

\begin{tabular}{|c|c|c|c|c|c|c|c|c|c|c|}
\hline & & \multicolumn{2}{|c|}{$\begin{array}{l}\text { DECENTRALIZED } \\
\text { COL. (I) }\end{array}$} & \multicolumn{2}{|c|}{$\begin{array}{l}\text { MNFINF } \\
\text { COL. (II) }\end{array}$} & \multicolumn{2}{|c|}{$\begin{array}{l}\text { RCYINF } \\
\text { COL. (III) }\end{array}$} & \multirow{2}{*}{$\begin{array}{l}\text { MAX(MAX (Dec., } \\
\text { MNFINF, } \\
\text { RCYINF)) } \\
\text { COL. (IV) } \\
\end{array}$} & \multirow{2}{*}{$\begin{array}{l}\text { MIN(MAX(Dec., } \\
\text { MNFINF, } \\
\text { RCYINF)) } \\
\text { COL. (V) } \\
\end{array}$} & \multirow[t]{2}{*}{ CHANGE } \\
\hline Environmental performance & & MAS & FCFAM & MAS & FCFAM & MAS & FCFAM & & & \\
\hline $\begin{array}{l}\text { Procurement cost of manufacturer with recycled-material } \\
\operatorname{supplier}\left(O_{m}^{r}\right)\end{array}$ & & 232800 & 234800 & 68000 & 434100 & 617800 & 2641300 & 2641300 & 234800 & 10.2491 \\
\hline Procurement cost of recycled-material supplier $\left(O_{r}\right)$ & & 116550 & 118900 & 34000 & 217050 & 308900 & 1328800 & 1328800 & 118900 & 10.1757 \\
\hline Collection investment made by recycled-material $\operatorname{supplier}\left(G_{r}\right)$ & & 336 & 336 & 42.5 & 42.5 & 62.5 & 1425 & 1425 & 42.5 & 32.5294 \\
\hline \multirow[t]{2}{*}{ Emission cost (Ship) } & & 582400000 & 416000000 & 832000000 & 2121600000 & 3328000000 & 3496000000 & 3496000000 & 582400000 & 5.0027 \\
\hline & $\begin{array}{c}\text { Total } \\
\text { environmental } \\
\text { Cost } \\
\end{array}$ & 582749686 & 416354036 & 832102042.5 & 2122251193 & 3328926763 & 3499971525 & 3499971525 & 582749686 & 5.0059 \\
\hline \multicolumn{11}{|l|}{ Economic performance } \\
\hline Manufacturer & & & & & & & & $\begin{array}{c}\text { MIN(MIN (Dec., } \\
\text { MNFINF, } \\
\text { RCYINF)) }\end{array}$ & $\begin{array}{c}\text { MAX(MIN } \\
\text { (Dec., MNFINF, } \\
\text { RCYINF)) }\end{array}$ & CHANGE \\
\hline Ordering cost with recycled supplier & & 420 & 630 & 630 & 400 & 420 & 415 & 400 & 420 & -0.0476 \\
\hline Ordering cost with new-raw-material supplier & & 10 & 15 & 15 & 40 & 10 & 10 & 10 & 15 & -0.3333 \\
\hline Holding cost & & 0 & 0 & 0 & 51.2861 & 422.7265 & 1516.5029 & 0 & 422.7265 & -1.0000 \\
\hline Shortage cost & & 40357.0060 & 40243.4306 & 29070.6287 & 2528.1557 & 34.6932 & 48.8713 & 34.6932 & 40243.4306 & -0.9991 \\
\hline Total inventory cost & & 40787.0061 & 40888.4306 & 29715.6287 & 3019.4418 & 887.4196 & 1990.3743 & 887.4196 & 40787.0061 & -0.9782 \\
\hline Waiting cost of ship & & 5526.9117 & 2937.6319 & 3748.0831 & 1464.4815 & 1287.7783 & 1299.4244 & 1287.7783 & 2937.6319 & -0.5616 \\
\hline Total Operational cost of Transportation & & 36814.0449 & 36162.1432 & 45618.6703 & 107047.6483 & 116693.5873 & 125931.2010 & 36162.1433 & 116693.5873 & -0.6901 \\
\hline \multicolumn{11}{|l|}{ Recycled-material supplier } \\
\hline Ordering cost with CEUM & & 72 & 48 & 11 & 11 & 3 & 23 & 3 & 48 & -0.9375 \\
\hline Set-up cost of machine (for MAS and FCFAM) & & 98 & 2477 & 11 & 8694 & 26 & 53130 & 11 & 98 & -0.8877 \\
\hline Holding cost & & 0.4143 & 1.9501 & 0.0997 & 3.1692 & 0.7966 & 8.9537 & 0.0997 & 0.7966 & -0.8747 \\
\hline Shortage cost & & 117.3135 & 43.4531 & 4464.9596 & 59.4826 & 139037.8053 & 544.21175 & 43.4531 & 544.2117 & -0.9201 \\
\hline \multicolumn{11}{|l|}{ New-raw-material supplier } \\
\hline Ordering cost & & 340 & 212.5 & 212.5 & 212.5 & 212.5 & 340 & 212.5 & 212.5 & 0 \\
\hline Holding cost & & 1.4995 & 1.16433464 & 6.599420586 & 0.127486669 & 0.002448189 & 0.00387305 & 0.00244819 & 1.499509604 & -0.9983 \\
\hline \multirow[t]{2}{*}{ Shortage cost } & & 5711.5516 & 5869.8608 & 303.4382 & 7638.2132 & 236435.4037 & 78670.1904 & 303.4382 & 78670.1904 & -0.9961 \\
\hline & $\begin{array}{c}\text { Total Economic } \\
\text { cost }\end{array}$ & 130425.2811 & 129651.4761 & 113881.195 & 131200.1729 & 495482.0219 & 263953.0110 & & & \\
\hline
\end{tabular}


Table B.2: ANOM and ANOVA of RCYINF-FCFAM, Decentralized-FCFAM, and MNFINF-MAS strategies

\begin{tabular}{|c|c|c|c|c|c|c|}
\hline \multirow[b]{2}{*}{ Performance } & \multirow[b]{2}{*}{$\begin{array}{l}\text { Information } \\
\text { Policy }\end{array}$} & \multirow[b]{2}{*}{$\begin{array}{c}\text { FBD } \\
\text { Strategy }\end{array}$} & \multirow[b]{2}{*}{$\begin{array}{c}\text { ANOM } \\
\text { (Optimal Levels) }\end{array}$} & \multicolumn{3}{|c|}{ ANOVA } \\
\hline & & & & $\begin{array}{l}\text { Significant } \\
\text { factor(s) }\end{array}$ & $\begin{array}{l}\text { Error } \\
\text { Variance } \\
\sigma_{e}^{2}(\mathrm{~dB})^{2} \\
\end{array}$ & F-ratio \\
\hline \multirow{9}{*}{ Environment } & \multirow{9}{*}{ RCYINF } & \multirow{9}{*}{ FCFAM } & \multirow{9}{*}{$\begin{array}{l}D 1, N s 2, N r 1, N t 1 \\
K m 1, K r 1, K n 2, S_{e t} 1, \\
C E U M 1, I P 1, C I 2\end{array}$} & $D$ & & 422756.30 \\
\hline & & & & Ns & & 1766.37 \\
\hline & & & & $\mathrm{Nr}$ & & 42.14 \\
\hline & & & & $N t$ & & 7366.88 \\
\hline & & & & $\mathrm{Km}$ & $0.00022(\mathrm{~dB})^{2}$ & 77.44 \\
\hline & & & & $K r$ & & 34.88 \\
\hline & & & & Kn & & 167.51 \\
\hline & & & & $S_{e t}$ & & 133.42 \\
\hline & & & & $C I$ & & 22.59 \\
\hline \multirow[b]{3}{*}{ Economic } & \multirow[b]{2}{*}{ Decentralized } & \multirow[b]{2}{*}{ FCFAM } & \multirow{2}{*}{$\begin{array}{l}D 1, N s 1, N r 2, N t 2, \\
K m 2, K r 1, K n 1, S_{e t} 1, \\
C E U M 1, I P 2, \text { and } C 12\end{array}$} & CEUM & \multirow[b]{2}{*}{$0.9141(\mathrm{~dB})^{2}$} & 3325.29 \\
\hline & & & & $I P$ & & 21.54 \\
\hline & MNFINF & MAS & $\begin{array}{l}D 1, N s 2, N r 1, N t 1, \\
K m 2, K r 2, K n 1, S_{e t} 1, \\
C E U M 1, I P 2, \text { and } C I 1\end{array}$ & $D$ & $0.3579(\mathrm{~dB})^{2}$ & 150.55 \\
\hline
\end{tabular}

Table B.3: Results of additivity test for RCYINF-FCFAM, Decentralized-FCFAM, and MNFINF-MAS strategies

\begin{tabular}{|c|c|c|c|c|c|c|c|}
\hline Performance & Information Policy & FBD rule & $\begin{array}{l}\eta_{\text {(observed }} \\
\text { optimal) }\end{array}$ & $\eta_{\text {(predicted optimal) }}$ & $\begin{array}{l}\text { Predicted } \\
\text { error }\end{array}$ & $\begin{array}{l}\text { Variance } \\
\text { of } \\
\text { Predicted } \\
\text { error }\end{array}$ & $\begin{array}{l}\text { 2-Standard } \\
\text { deviation } \\
\text { confidence } \\
\text { limit }\end{array}$ \\
\hline Environment & RCYINF & FCFAM & -192.8020 & -192.8087 & -0.0071 & 0.0002 & \pm 0.0304 \\
\hline \multicolumn{8}{|l|}{ Economic } \\
\hline & Decentralized & FCFAM & -180.6100 & -181.0666 & 0.4562 & 0.4113 & \pm 1.2827 \\
\hline & MNFINF & MAS & -187.589 & -188.2700 & 0.6813 & 0.1312 & \pm 0.7245 \\
\hline
\end{tabular}

